\title{
LA IMPORTANCIA DE LA CARTOGRAFÍA HISTÓRICA EN LA ELABORACIÓN DE MAPAS DE PELIGROSIDAD DE INUNDACIÓN EN EL CONTEXTO DEL CAMBIO CLIMÁTICO: PROPUESTAS PARA LA RAMBLA DE ABANILLA (ALICANTE)
}

\author{
Antonio Oliva Cañizares \\ Universidad de Alicante \\ antoniogeografia1@gmail.com \\ ORCID iD: https://orcid.org/0000-0001-6222-5852 \\ Jorge Olcina Cantos \\ Universidad de Alicante. \\ jorge.olcina@ua.es \\ ORCID iD: https://orcid.org/0000-0002-4846-8126
}

Cómo citar este artículo/citation: Oliva Cañizares, Antonio y Olcina Cantos, Jorge (2021). La importancia de la cartografía histórica en la elaboración de mapas de peligrosidad de inundación en el contexto del cambio climático: propuestas para la Rambla de Abanilla (Alicante). Estudios Geográficos, 82 (290), e069. https://doi.org/10.3989/estgeogr.202081.081

\begin{abstract}
RESUMEN: La rambla de Abanilla es un curso fluvial del sureste ibérico, generalmente seco, que se reactiva en momentos de precipitaciones intensas, generando anegaciones en su tramo final, en la Vega Baja del Segura (Alicante). El objetivo de esta investigación es determinar el grado de peligrosidad existente en los municipios del tramo bajo que fueron afectados en el episodio de septiembre de 2019. Se realiza una modelización del cauce y una serie mapas temáticos, cuyo resultado ha sido una cartografía de peligrosidad de inundación. Los resultados obtenidos muestran un nivel elevado de peligrosidad en el curso final del cauce (mayor que el realizado en la cartografía oficial existente SNCZI y PATRICOVA). Se analizan las propuestas que se han ido planteando tras cada evento de inundación por parte de diferentes organismos, y se proponen una serie de actuaciones para reducir la peligrosidad en los diferentes tramos de la rambla de Abanilla. La recuperación de sistemas tradicionales de riego se presenta como una posibilidad para reducir caudales de crecida y transformar el riesgo en un recurso, además de ser una medida de adaptación en el actual contexto de cambio climático.
\end{abstract}

PALABRAS CLAVE: rambla de Abanilla, cartografía histórica, mapas de peligrosidad, inundación, adaptación, cambio climático.

\section{THE IMPORTANCE OF HISTORICAL CARTOGRAPHY IN THE DEVELOPMENT OF FLOOD HAZARD MAPS IN THE CONTEXT OF CLIMATE CHANGE: PROPOSALS FOR RAMBLA DE ABANILLA (ALICANTE).}

ABSTRACT: Rambla de Abanilla is a southeaster Iberian river, usually dry, which is reactivated with intensive rainfall, generating floods in its lower reaches in Vega Baja del Segura (Alicante). The purpose of this research is to define the degree of hazard in the areas affected by the September 2019 flooding episode. A modeling of the riverbed and a series of thematic maps is carried out, resulting in flood hazard mapping. The results obtained show a high level of hazard in the final course of the river (larger than that made in the existing official SNCZI and PATRICOVA cartography). The proposals that have been put forward after each flooding event by different entities are analysed and a series of actions are proposed to reduce the hazard in the different section of the Rambla de Abanilla. The recovery of traditional irrigation systems is presented as a possibility to reduce flood flows and transforming risk into a resource in addition to being an adaptation measure in the current context of climate change.

KEY WORDS: Rambla Abanilla, historical cartography, hazards maps, floods, adaptation, climate change. 


\section{INTRODUCCIÓN}

Las inundaciones son el peligro natural más destacado de España, por la frecuencia de desarrollo y los daños (pérdidas económicas y víctimas humanas). En algunos ámbitos como el sureste peninsular tienen una incidencia muy destacada debido a la intensa transformación del que se ha experimentado en este espacio geográfico, sin tener en cuenta, en muchos casos, el grado de peligrosidad existente. De manera, que el factor principal que ha incrementado el riesgo ha sido la ocupación humana en espacios inundables, desde mediados del siglo pasado, lo que se traduce en un aumento notable de la exposición y de la vulnerabilidad.

Esta mayor exposición se debe a las abundantes actuaciones de ocupación territorial, que se han producido en el litoral mediterráneo español, y que no han tenido la vigilancia necesaria del cumplimiento normativo, en materia de requisitos ambientales existentes en los procesos de planificación. Es lo que algún autor ha denominado la "litoralización del riesgo" (Olcina, 2009), proceso ocurrido desde mediados del siglo pasado y que ha tenido un impulso enérgico en el último boom inmobiliario de los años noventa y comienzos del siglo actual, que originaron la mayor ocupación de espacios de riesgo de inundación ocurrida en nuestro país (Pérez Morales et al., 2015).

Nuestro país ocupa el quinto lugar de Europa por volumen de población expuesta a las inundaciones (2.3 millones de habitantes), siendo las áreas litorales, especialmente en la zona mediterránea, las que concentran un nivel de riesgo mayor ante este peligro natural (Perles, Olcina y Mérida, 2018). Cuestión que ya señalaba el informe sobre peligrosidad natural y tecnológica en Europa (ESPON, 2006) y que, en la actualidad, sigue destacando el Report 2020 Shared evidence for managing crises and disasters ante los peligros naturales en España (JCR, 2020).

Para reducir el riesgo, la población demanda actuaciones que eviten efectos catastróficos. En España este tipo de medidas se llevan a cabo, por lo general, tras un evento catastrófico (post-desastre). Así pues, las administraciones competentes apuestan por la solución común basada en medidas estructurales que en el caso de inundaciones supone la construcción de embalses, diques, muros de contención, canalización, encauzamiento, etc., con un elevado coste económico y ambiental (Olcina y Oliva, 2020a). White (1945) señalaba que cuando estas medidas se ven superadas por una gran crecida fluvial los daños económicos y sociales son mayores que en la situación previa a la construcción de las mismas. En contraposición a las mismas, surgen las actuaciones no estructurales o alternativas, que centran su estrategia en la gestión de las inundaciones, por medio de medidas como los sistemas de alerta temprana, la ordenación del territorio, la cartografía de riesgos naturales, planes de emergencia, seguros y la educación para el riesgo (Olcina y Oliva, 2020a), persiguiendo los objetivos marcados por la Directiva 60/2007/CE sobre la Evaluación y Gestión de las inundaciones y en un contexto más amplio, los establecidos por los Objetivos de DesarroIlo Sostenible (Objetivo núm. 13, Horizonte 2030).

El presente trabajo recoge un estudio, cuyos resultados se ofrecen como mapas de peligrosidad de un cauce denominado rambla de Abanilla, que se localiza en la provincia de Alicante (España), al NW de la comarca del Bajo Segura. Los objetivos de la presente investigación se resumen en cuatro:

a) Análisis y elaboración de cartografía propia de peligrosidad de la rambla de Abanilla.

b) Comparación con las cartografías oficiales existentes (SNCZI y PATRICOVA).

c) Determinación del grado de ocupación por usos antrópicos de la zona inundable.

d) Propuestas de actuación para reducir el riesgo de inundación existente debido a la alta peligrosidad de zonas próximas al cauce.

La elección de los objetivos planteados se debe a que existe una multiplicidad de elementos antrópicos que han ocupado las zonas inundables de dicho cauces, tales como núcleos poblacionales, viviendas rurales, infraestructuras agrícolas y viarias, e instalaciones industriales (naves), viéndose afectadas en momentos de crecida fluvial ordinaria y, sobre todo, extraordinarias.

Se estudian los efectos ocasionados por el episodio de septiembre de 2019, cuando una precipitación de carácter torrencial, llegó a descargar entre 150-300 $1 / \mathrm{m}^{2}$ en tan solo 2 horas en el área objeto de estudio (Olcina y Oliva, 2020a). En el total del episodio, algunos observatorios registraron $521 \mathrm{l} / \mathrm{m}^{2}$ (Orihuela), casi duplicando la precipitación media anual. La cuantía instantánea de la precipitación motivó la crecida del río Segura y la reactivación de numerosos cursos fluviales de régimen esporádico. El río Segura se desbordó en el casco urbano de Orihuela, anegando todas las calles más próximas al cauce. Asimismo, se produjeron varias roturas en diferentes motas del 
encauzamiento del río, obra realizada tras la riada ocurrida en noviembre de 1987 . Todo ello ocasionó el desbordamiento del mismo y el anegamiento de cientos de hectáreas de huerta, muy especialmente debido a la rotura del dique existente en la margen izquierda del nuevo cauce, en el puente que conecta Algorfa y Almoradí (CV-935). Las aguas desbordadas permanecieron diez días sobre la Vega Baja del Segura, causando graves daños en la actividad agrícola y en las viviendas.

Junto al desbordamiento del cauce principal, otros cauces menores, como la rambla de Abanilla, objeto del presente estudio, causaron asimismo el anegamiento en diferentes sectores a lo largo de su recorrido por la comarca del Bajo Segura (Fig. 1). Dicha rambla se desbordó, causando importantes daños económicos, en los términos municipales de Benferri, Orihuela y Redován. En Benferri, las aguas desbordadas anegaron las calles colindantes situadas en el margen izquierdo de la rambla. Asimismo, por su margen derecha, inundaron las casas del barrio del Cabezo, al encontrarse instaladas, prácticamente, en el lecho del cauce.

\section{Área de estudio: El río Chícamo-rambla de Abanilla.}

El río Chícamo está inserto en la unidad de la cuenca de Abanilla-Fortuna (Fig. 2), caracterizado en todo su tramo por la escasez e irregularidad de las lluvias compartidas por toda la cuenca Mediterránea (Manzano, 1987). El carácter intermitente, la condición de territorio con rexistasia que atraviesa su curso, la acusada pendiente y la fuerte erosión del suelo, hacen

FIGURA 1.

CRECIDA E INUNDACIONES DE LA RAMBLA DE ABANILLA EN EL EPISODIO DE SEPTIEMBRE 2019.
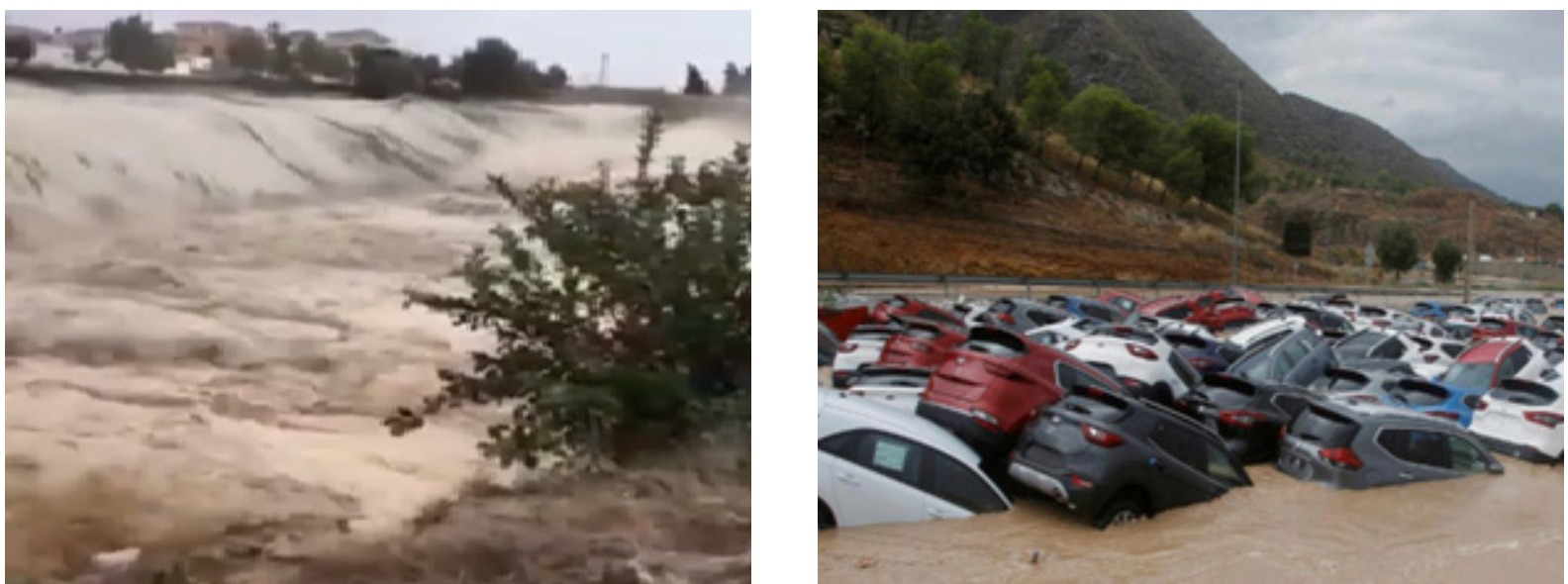

Fuente: Izquierda. Imagen extraída del vídeo realizado por Roberto López, facilitado por MeteOrihuela. Derecha. Efectos en el tramo final de la rambla, anegamiento del polígono industrial de Puente Alto (Orihuela).Diario El Mundo (13/09/2019).

FIGURA 2.

CUENCA DE LA RAMBLA DE ABANILLA
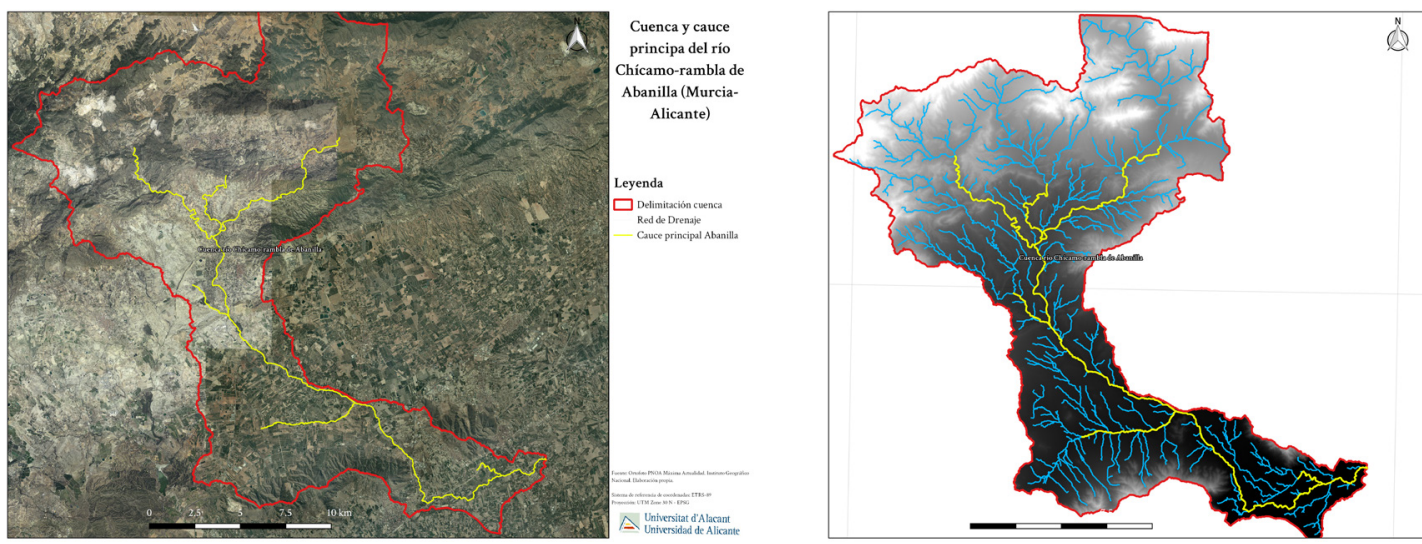

Fuente: Instituto Geográfico Nacional (IGN). Ortofoto PNOA Máxima Actualidad y Modelo Digital del Terreno -MDT 25m.Elaboración propia.

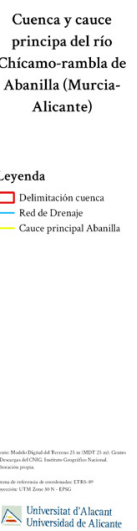


que la rambla de Abanilla presente una personalidad muy poderosa marcada por la gran virulencia de sus avenidas (Soriano, 2004).Sobre todo, en su tramo bajo donde se reciben coladas de fango que generan daños importantes en los cultivos, hábitat rural e infraestructuras.

El topónimo del río Chícamo continúa hasta El Partidor (Murcia), donde el cauce pasa a denominarse rambla de Abanilla. A lo largo de la llanura de inundación del río-rambla, se va a generar una huerta destacando el papel fundamental del aprovechamiento de estas crecidas, utilizando las aguas de avenida para el riego de cultivos. Aguas abajo se encuentra la población de Abanilla, que recibe el nombre del curso fluvial que circula en sus proximidades. En tierras alicantinas, desciende hasta Benferri, donde se bifurca en dos ramales principales, por la presencia de un azud histórico que divide en dos el cauce. Uno de se dirige, en un sentido norte-sur hacia Orihuela, donde vierte sus aguas a la huerta que se encuentra entre la sierra de Orihuela y Callosa del Segura. Se trata de un gran abanico aluvial formado por sucesivas deposiciones de sedimentos transportados por este ramal de la rambla en sus crecidas. El otro continua, en un sentido oeste-este, hacia el noroeste de la sierra de Callosa, recibiendo el nombre de rambla de Redován, sufriendo una inflexión en su recorrido, al cambiar su sentido a N-S hacia la huerta de Redován y Orihuela.

Asimismo, gracias a la cartografía histórica se conoce que la rambla de Redován se prolongaba en otro cauce hacia el término municipal de Cox, aunque hoy en día, se ha perdido entre verdas, caminos y ocupaciones antrópica del suelo. Estos ramales son los principales causantes que originan inundaciones en los términos municipales mencionados.

Como se observa en la Tabla 1, el índice de sinuosidad obtenido muestra un resultado de un cauce meandrizante con una importante fuerza erosiva, capaz de crear crecidas súbitas e inundaciones, debido a la escasa infiltración (margas y arcillas) que presenta el terreno. Empero, el cauce sinuoso se caracteriza por el lento discurrir en los tramos bajos, lo que se traduce en una posibilidad de aprovechamiento de las aguas, como lo hicieron nuestros antepasados; o bien, como un elemento de riesgo para la población, a considerar.

TABLA 1.

CARACTERÍSTICAS MORFOMÉTRICAS DE LA CUENCA DEL RÍO CHÍCAMO-ABANILLA

\begin{tabular}{|c|c|c|c|c|c|c|c|}
\hline \multicolumn{8}{|l|}{ CUENCA } \\
\hline$A\left(\mathrm{~km}^{2}\right)$ & $P(\mathrm{~km})$ & $D A(m)$ & $L A(\mathrm{~km})$ & $L c(\mathrm{~km})$ & $L v(\mathrm{~km})$ & Is & Pc (\%) \\
\hline 322,4 & 173 & 1.060 & 34,2 & 55,74 & 27,2 & $\begin{array}{l}2,05 \text { (meandrizante e } \\
\text { importante fuerza erosiva) }\end{array}$ & $1,15 \%$ \\
\hline$W(\mathrm{~km})$ & $K f$ & Kc & $\operatorname{Re}$ & & & & \\
\hline 5,78 & $\begin{array}{l}0,28 \text { (cuenca } \\
\text { alargada) }\end{array}$ & $\begin{array}{l}2,7 \\
\text { (cuenca } \\
\text { alargada) }\end{array}$ & $\begin{array}{l}0,59 \\
\text { (cuenca alargada) }\end{array}$ & & & & \\
\hline \multicolumn{8}{|c|}{ RED DE DRENAJE } \\
\hline$u$ & 1 & 2 & 3 & 4 & 5 & TOTAL & \\
\hline $\mathrm{Nu}$ & 344 & 151 & 105 & 51 & 33 & 684 & \\
\hline$R \boldsymbol{B}$ & 2,28 & 1,44 & 2,05 & 1,55 & - & $1,83^{*}$ & \\
\hline$L t(k m)$ & 388.809 & 9.332 & 88,3 & 40,38 & 34,7 & $398.304,38$ & \\
\hline$R I$ & - & 0,02 & 0,002 & 0,46 & 0,86 & 0,34 & \\
\hline$D d\left(\mathbf{k m} / \mathrm{km}^{2}\right)$ & $c t$ & $\rho$ & Tipo de Red de drenaje & & & & \\
\hline 1235,44 & 1.318 & $0,18 * *$ & Dentrítica & & & & \\
\hline
\end{tabular}

*Valores inferiores a 3 son propios de las cuencas muy ramificadas, redondeadas o elongadas, proclives a generar crecidas súbitas e inundaciones.

**Valor próximo al 0 indica que apenas existe infiltración en el suelo, y que, por tanto, la escorrentía superficial se forma antes e incrementa sus niveles de caudal en poco tiempo. Elaboración propia.

1 Las abreviaturas para la cuenca representan: $A$ al área de la cuenca; $P$ el perímetro de la cuenca; $D A$ el Desnivel Altitudinal; $L A$ la Longitud de la Cuenca; $L c$ la Longitud del cauce; $L v$ la longitud del valle; IS el Índice de Sinuosidad; Pc la Pendiente media del cauce principal; $W$ la anchura de la cuenca; $K f$ el Coeficiente de forma; $K c$ el Coeficiente de compacidad; Re la Razón de Elongación; $U$ el Orden de los cauces; $N u$ la cantidad total de cauces; $R b$ la Relación de bifurcación; Lt la Longitud total de los cauces; $D d$ la Densidad de drenaje; $R I$ la Relación de Longitud; $C t$ el coeficiente de torrencialidad; y $\rho$ el Coeficiente de almacenamiento. 
En lo referente al aprovechamiento tradicional, varios autores han trabajado sobre el aprovechamiento de las aguas por medio de sistema de aterrazamientos, derivación de aguas y aljibes (Morales Gil, 1969; Box Amorós, 1995; Gil Meseguer y Gómez Espín, 2012; Morote Seguido, 2013; Sánchez Almodóvar, 2018), así como de la presencia de molinos en la cuenca Fortuna-Abanilla, para el riego de cultivos y actividades molineras (Castillo Meseguer, Calero Sáez, Palao García, Pérez Bolumar, Rodríguez Pérez y Gómez Espín, 1995; Gil Meseguer y Gómez Espín, 2012) o la reducción de la peligrosidad de inundación de la rambla de análisis, recuperando los sistemas de regadío tradicional (Marco Molina, Giménez Font, Padilla Blanco, García Botella, Prieto Cerdán, 2020).Incluso Madoz recogía que "En el mismo nacimiento del Chícamo se construyó hace 6 años un molino harinero; á poco otros dos en la corriente de Zurca, y otros dos existen dentro de la huerta" (p.39)

Se señala la presencia de balsas en los propios cauces de barrancos o ramblas donde se almacenaban volúmenes de agua que se aprovechaban en momentos de sequía (Castillo Meseguer et al., 1995). Asimismo, se tiene constancia de que los recursos hídricos de la rambla de Abanilla son aptos para el cultivo de melón, tomates y secano "mejorado" en la zona de Benferri y La Matanza (Orihuela). Ello indica que el río Chícamo ha sido importante para todos los habitantes que conviven con él, de ahí que queden restos del sistema de riego por boquera, la presencia de azudes, o restos de molinos harineros. Madoz señalaba en su definición de Benferri, que esta localidad se encontraba en el llano próximo de la rambla de Abanilla y que el terreno era aprovechado generalmente por el secano con plantaciones de olivos y algunas higueras regándose únicamente de las avenidas de la rambla de Abanilla, cuyos productos eran, principalmente, trigo, cebada, aceite, higos, sosa y barrilla.

Estas actividades tradicionales han sido abandonadas a partir de la segunda mitad del siglo $X X$, provocando su deterioro y desaparición, y cuyo proceso de abandono se traduce en un incremento de la escorrentía (peligrosidad) y, en última instancia, del riesgo de inundación por el alto grado de transformación y ocupación de la zona inundable. Un factor que influyó para que los daños fueran mayores es el abandono de los azudes que de forma histórica laminaban el agua resultando dañados ${ }^{2}$.

2 Pamies, D. (20/07/2020). El río Chícamo reclama sus escrituras. Diario Información. Recuperado dehttps://www.diarioinformacion.com/vega-baja/2020/07/20/rio-chicamo-re-
El comportamiento irregular de las lluvias y las características climáticas mediterráneas, superan los cálculos probabilísticos basados en los periodos de retorno. Lo lógico sería basarse en el dato máximo de precipitación registrada en las cuencas, para la toma de medidas, aunque el Mediterráneo siempre supera sus propios récords.

El episodio de inundación de septiembre de 2019 y las inundaciones acaecidas por la rambla de Abanilla, registraron valores récords de precipitación, según los datos recopilados por el Laboratorio de Climatología de la Universidad de Alicante ${ }^{3}$, oscilarían entre los 280-300 l/ $\mathrm{m}^{2}$, el episodio total en la zona de Benferri. En Orihuela se alcanzaron los 521,6 l/ $\mathrm{m}^{2}$ totales del episodio, donde $250 \mathrm{l} / \mathrm{m}^{2}$ se registraron en tan sólo dos horas, generando numeras anegaciones (Olcina y Oliva, 2020b). No obstante, este episodio de inundación también ha tenido efectos positivos por el aporte de sedimentos y que, en la actualidad, gracias al exceso de lluvias se ha redescubierto los caminos de agua, a su paso por Benferri y que, todavía, genera algunos problemas de inundaciones parciales en Redován. Además, un particular recoge sus aguas para revenderlas aprovechando un foso de una cantera abandonada de la misma localidad ${ }^{4}$.

Sin embargo, desde los años cincuenta de la pasada centuria, cada vez que se producía un evento de lluvia torrencial, la rambla de Abanilla se reactivaba generando inundaciones en los mismos sectores que en la actualidad: Benferri, Redován, El Escorratel, carretera Benferri a Orihuela (CV-870 y CV-930), el polígono industrial de Puente Alto, Camino Viejo de Callosa, La Campaneta, Badén Mudamiento y la N-340. Asimismo, Balboa (1997) señalaba que el Barrio Cabezo era el gran problema al no respetar los $15 \mathrm{~m}$ que establece el ordenamiento urbanístico de Benferri, a ambos lados de la rambla de Abanilla como franja de uso público. No obstante, el autor le resta importancia al señalar que al tener un cauce ancho los problemas no deben ser "graves".

Esta afirmación es incorrecta ya que la propia modelización del Sistema Nacional de Cartografías de Zonas Inundables (SNCZI) muestra que el Barrio Cabezo, se

clama-escrituras/2283989.html (Consultado: 20/07/2020).

3 Laboratorio de Climatología de la Universidad de Alicante (2019). Precipitación total registrada en el episodio de septiembre de 2019. Recuperado de: https://www.facebook.com/labclimaUA/photos /a.487357624770773/1660184870821370

4 Vid. nota 1. 
FIGURA 3.

COMPARATIVA DE ZONAS INUNDABLES EN EL TRAMO FINAL DE LA RAMBLA DE ABANILLA SEGÚN LAS CARTOGRAFÍAS OFICIALES DEL SNCZI Y DEL PATRICOVA.
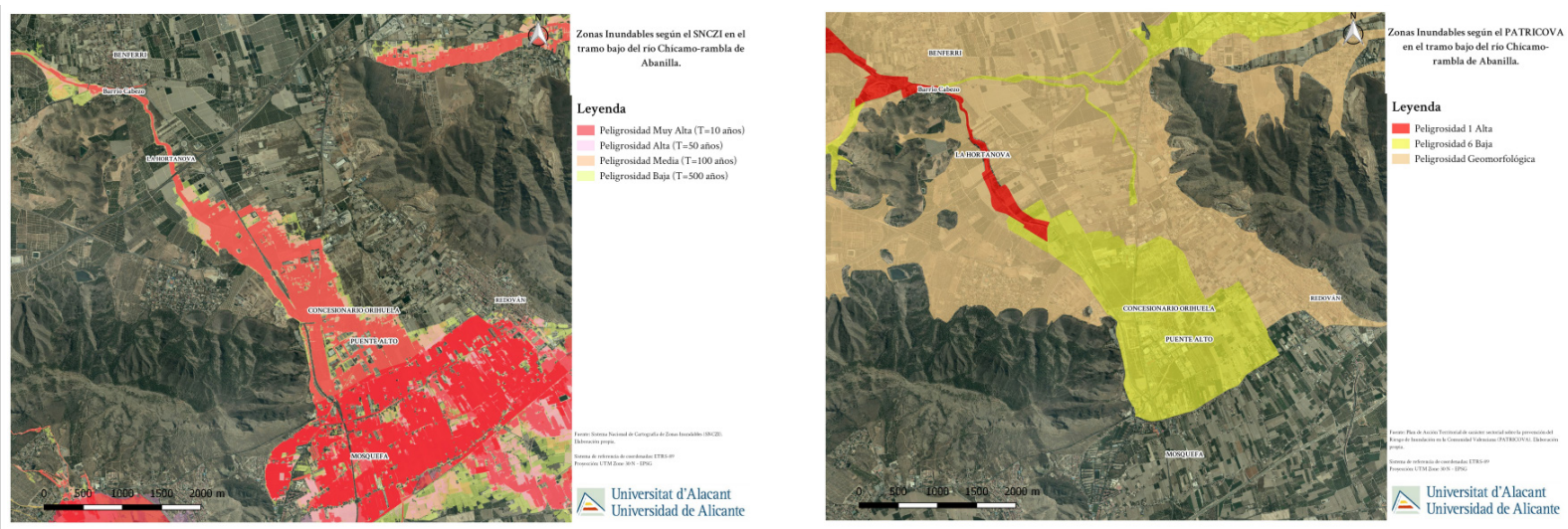

Fuente: Imagen superior. Sistema Nacional de Cartografías de Zonas Inundables (SNCZI). Imagen inferior. Plan de Acción Territorial de carácter sectorial sobre la prevención de los Riesgos de Inundación en la Comunidad Valenciana (PATRICOVA). Elaboración propia.

ve afectado por inundaciones frecuentes (T50 años), media u ocasional (T100 años) y baja o excepcional (T500 años).

Asimismo, con la revisión del Plan de Acción Territorial de carácter sectorial sobre la prevención de los Riesgos de Inundación en la Comunidad Valenciana (PATRICOVA), muestra que es un espacio clasificado con una Peligrosidad 1 (Frecuencia 25 años y calado alto $>0,8 \mathrm{~m}$ ), una Peligrosidad 6 (Frecuencia 500 años y calado bajo $<0,8 \mathrm{~m}$ ) y una Peligrosidad Geomorfológica (Inundación) (Fig. 3). A ello se le suman los graves efectos del episodio de septiembre de 2019, lo que permite la obtención de una cartografía más detallada y precisa que las anteriores, al tener en cuenta diferentes variables $y$, sobre todo, al tratarla a escala municipal (1:5.000).

Aunque, la rambla de Abanilla se ensanche en este espacio, el cauce apenas tiene profundidad lo que provoca que las aguas afecten en mayor medida. Además, las aguas proceden de una zona de estrechamiento, por lo que a modo de manguera, la presión de la avenida la dota de mayor virulencia en este sector. Hay que sumar también, la presencia de obstáculos como la carretera CV-869, instalada en el mismo lecho de la rambla a ras de suelo, en la cual se produjo la rotura de parte de ella. Asimismo, se encuentra la presencia del azud histórico de Benferri que desvía las aguas hacia Redován, cuya avenida provocó roturas y desperfectos en el mismo, lo que ha obligado a la Demarcación Hidrográfica del Segura a invertir 1 millón euros para reparar, asegurar paredes y limpiar el lecho del cauce ${ }^{5}$.

5 Vid. nota 1.
Respecto al tramo de la rambla en Redován, ésta anega el polígono industrial de Puente Alto, el campo, la huerta, la mitad sur del núcleo de Redován y las zonas ajardinadas al sur de la sierra de Callosa, además de poder dirigirse hacia Almoradí y Dolores.

Para demostrar que el comportamiento de este tipo de ramblas mediterráneas tienen poco que ver con el cálculo estadístico de los periodos de retorno, se ha realizado un estudio sobre las reactivaciones de la rambla de Abanilla, en la que se observa de manera clara que no se rige a los cálculos probabilísticos sino que dependen de la intensidad y cantidad de las precipitaciones. Así, en la década de los sesenta existen noticias que indican que la rambla de Abanilla se desborda hasta diez veces, en menos de diez años, con más de una crecida importante por año (Olcina, 1994) generando inundaciones y daños sociales-económicos.

Por su parte, para solventar los problemas de anegación que produce la rambla de Abanilla, la DHS en su Plan Hidrológico de Cuenca del Segura (2015-2021) $y$, en concreto, en el capítulo del Plan de Gestión de Inundaciones, recoge una serie de propuestas a realizar en la cuenca de la rambla de Abanilla, como su encauzamiento en el tramo final que, en la actualidad, no ha sido ejecutado. En la publicación, asimismo, del Esquema Provisional de Temas Importantes (EPTI) de la cuenca del Segura, en su ficha 11 dedicada a la Gestión del Riesgo de Inundación, no se contempla ninguna medida al respecto. Tan solo trata cuestiones generales relacionadas con la temática de las inundaciones $^{6}$.

6 Demarcación Hidrográfica del Segura (2020). Esquema Provisional de Temas Importantes de la Demarcación Hidrográ- 
A todo ello se suma el hecho de que los municipios de Benferri y Redován, carecen de un Plan de Emergencias Municipal. No obstante, tras el episodio de inundación de septiembre de 2019, los municipios de la Vega Baja del Segura van a elaborar sus planes de emergencia con ayuda de la Dirección General de Emergencias de la Generalitat Valenciana, según se contempla en el Plan Vega Baja Renhace ${ }^{7}$. Orihuela, por su parte, sí dispone de Plan de Emergencias Municipal, donde se menciona en tres ocasiones el término municipal de Benferri, pero no se señalan medidas de actuación ante una emergencia como las inundaciones en dicho municipio.

\section{FUENTES Y MÉTODOS}

La realización de la presente investigación ha sido fruto de una búsqueda de información histórica sobre la rambla de Abanilla. La consulta de artículos científicos sobre dicho cauce y la cartografía histórica, ha permitido encontrar unos mapas históricos interesantes que explicaban a la perfección las zonas inundadas en el episodio de septiembre de 2019. En ellos se ha observado las numerosas bifurcaciones que presenta el cauce de la rambla a la altura de Benferri, así como todo el sistema de aprovechamiento por medio de los vuelos históricos de Ruíz de Alda (1929-1930) y vuelo Americano Serie B (1956) consultado en la fototeca del Instituto Cartográfico Valenciano (ICV).

Ello ha permitido la elaboración de una cartografía base que recoge el cauce completo de la rambla de Abanilla y algunos de los niveles de su sistema de boqueras. Durante la realización de este mapa, se ha ido observando la presencia de abanicos fluviales, por lo que se ha elaborado una cartografía geomorfológica que, unida a los sistemas de boqueras y acequias, se aprecia el método de puesta en cultivo de estos espacios inundables, a la vez que se han identificado una serie de infraestructuras ubicadas en toda esta área inundable entre Orihuela y Redován.

Con la obtención del Modelo Digital del Terreno 25 $\mathrm{m}$, se ha podido delimitar la cuenca la rambla de Abanilla por medio de las herramientas de SAGA que presenta el QGIS. Una vez obtenida la cuenca de drena-

fica del Segura. Recuperado de: https://www.chsegura.es/ chs/planificacionydma/planificacion21-27/proceso.html y https://www.chsegura.es/export/descargas/planificacionyd$\mathrm{ma} /$ planificacion21-27/docsdescarga/ficha-11.pdf

7 Generalitat Valenciana (2020). Plan Vega Baja Renhace. Recuperado de: http://www.presidencia.gva.es/es/web/ vega-Renhace je de dicho cauce, se ha procedido a medir y realizar los cálculos pertinentes, para actualizar y conocer las condiciones morfométricas de dicho espacio geográfico (Tabla 1).

A continuación, se ha realizado dos mapas sobre la cartografía de inundación de las fuentes oficiales como el Sistema Nacional de Cartografías de Zonas Inundables (SNCZI) y el Plan de Acción Territorio de carácter sectorial sobre la prevención del Riesgo de Inundación en la Comunidad Valenciana (PATRICOVA), para poder conocer las zonas inundables consideradas por los organismos competentes. En este sentido, se ha realizado una comparativa entre los resultados obtenidos con los que ofrecen el SNCZI y el PATRICOVA. Asimismo, se han sumado las superficies inundadas del PATRICOVA como del SNCZI con la finalidad de obtener una zona completa de inundación referente a la rambla de Abanilla.

Hecho que permite identificar las edificaciones (en hectáreas) de los municipios de Benferri, Orihuela, Redován y Cox, que se encuentran ubicadas en zonas inundables, a la vez que se siguen ocupando más estos espacios por los procesos urbanísticos, incrementando la exposición de las personas.

Posteriormente, se ha llevado a cabo la elaboración de la modelización con el programa HEC-RAS. Para ello ha sido necesaria la obtención del Modelo Digital del Terreno (MDT $05 \mathrm{~m}$ ), obtenido del Instituto Nacional de Geografía. Una vez introducido el MDT en el programa HEC-RAS se han dibujado las geometrías correspondientes (río, márgenes y zonas inundables) a lo largo del tramo de la rambla de Abanilla. Se han tenido que utilizar dos geometrías: la primera parte desde tierras murcianas-Benferri hasta Orihuela; y la segunda desde Benferri hasta Redován. Para el primer tramo se ha introducido un caudal de $600 \mathrm{~m}^{3} / \mathrm{s}$ ya que los resultados obtenidos por la modelización, se asemejan a las zonas afectadas por la inundación del episodio de septiembre de 2019. Asimismo, dicho valor resulta ser bastante razonable ya que se conoce que un total de $200 \mathrm{~m}^{3} / \mathrm{s}$ fueron desviados por el canal de Abanilla hacia el embalse de Santomera, lo que implica que el caudal circulante por el cauce principal tendría un valor superior al indicado. Dicho embalse tuvo que desaguar casi $20 \mathrm{hm}^{3}$ por vía de urgencia por las aguas provenientes de la rambla, y que podrían explicar uno de los motivos de la rotura de las motas de Almoradí. Todas estas cuestiones incentivan a pensar que el caudal circulante real oscilaría entre los 400$650 \mathrm{~m}^{3} / \mathrm{s}$, en su momento de mayor crecida. Además, teniendo en cuenta la cartografía oficial del PATRICO- 
VA y SNCZI, dichos resultados podrían clasificarse en los periodos de retorno entre 25-50 años.

En lo que respecta al segundo tramo, correspondiente a la denominada rambla de Redován, se ha introducido un caudal de $200 \mathrm{~m}^{3} / \mathrm{s}$, el cual ya ha generado resultados importantes e interesantes respecto a las zonas anegadas de dicho municipio. Por su parte, en las condiciones de entrada se ha introducido un régimen de profundidad crítico. Por último, se han incluido los valores de Manning correspondientes a la rugosidad según el uso del suelo. En este caso se ha introducido un valor 0.025 para el río/cauce y de 0.05 referente a las zonas de pradera que presentan características similares a las llanuras de inundación.

Seguidamente se ha realizado cuatro mapas de peligrosidad de inundación cuyos valores cuantitativos se han expresado en términos cualitativos en cinco categorías: "Muy Alta", "Alta”, "Media”, "Baja” y "Muy Baja". La obtención de este mapa como resultado final, proviene de la superposición de varios mapas temáticos que han permitido conocer el nivel de peligrosidad. Para ello, se ha obtenido de las zonas elegidas un mapa de pendientes, uno de litología, uno de cartografía histórica, uno de peligrosidad geomorfológica, un mapa de peligrosidad de inundación del PATRICOVA (500 años), uno del SNCZI (500 años) y, por último, el calado y la velocidad obtenidos de la modelización. A cada mapa se le ha asignado un valor de peligrosidad, de menor a mayor peligrosidad ( 1 al $5)$, en función de la mayor influencia de cara a una inundación. Conviene señalar que algunos datos varían en función de la zona de estudio. No obstante, se procede a poner algunos ejemplos para una mayor comprensión.

Esto son una serie de ejemplos de valores introducidos en el programa de QGIS en relación a la pendiente, litología y calados. Las capas restantes seguirían la misma metodología pero por motivos de extensión no se añaden. En este caso quedaría por otorgarle un valor de peligrosidad a las capas de peligrosidad geomorfológica, PATRICOVA, SNCZI y velocidad. Éste último de manera idéntica al ejemplo de los calados (Tabla 2).

Como se observa en el ejemplo de las pendientes (Tabla 2), se le asigna un elevado valor de peligrosidad, en función de si son muy pronunciadas o si se

TABLA 2.

EJEMPLO DE VALORES ASIGNADOS DE PELIGROSIDAD EN FUNCIÓN DE LA PENDIENTE Y LITOLOGÍA

\begin{tabular}{|c|c|c|c|c|c|c|}
\hline \multicolumn{7}{|c|}{ Ejemplo de Pendientes en Benferri } \\
\hline ID & \multicolumn{2}{|c|}{$\begin{array}{c}\text { Reclasificación pendientes } \\
\text { (intervalos) }\end{array}$} & Valor Pendiente & Descripción & $\begin{array}{c}\text { Valor de } \\
\text { Peligrosidad }\end{array}$ & 4 \\
\hline $\mathbf{1}$ & -9999 & 7 & 1 & Nula & Ascasa & Alta \\
\hline $\mathbf{2}$ & 7 & 14 & 2 & Media & 2 & Buy Baja \\
\hline $\mathbf{3}$ & 14 & 21 & 3 & Pronunciada & 3 \\
\hline $\mathbf{4}$ & 21 & 28 & 4 & Muy Pronunciada & 5 \\
\hline $\mathbf{5}$ & 28 & 9999 & 5 & & Media \\
\hline
\end{tabular}

\begin{tabular}{|c|c|c|}
\hline \multicolumn{2}{|c|}{ Ejemplo de Litología en Puente Alto } \\
\hline ID & Litología & Valor de Peligrosidad \\
\hline $\mathbf{1}$ & Limos y Arenas & 5 \\
\hline $\mathbf{2}$ & Arenas, Gravas y Cantos & 2 \\
\hline $\mathbf{3}$ & Rocas carbonatadas & 1 \\
\hline
\end{tabular}

\begin{tabular}{|c|c|c|c|c|}
\hline \multicolumn{5}{|c|}{ Ejemplo de calado en las zonas de estudio } \\
\hline ID & \multicolumn{2}{|c|}{$\begin{array}{c}\text { Reclasificación de calados } \\
\text { (intervalos) }\end{array}$} & Valor de Calados & Valor de Peligrosidad \\
\hline $\mathbf{1}$ & -9999 & 1 & 1 & 1 \\
\hline $\mathbf{2}$ & 1 & 2 & 2 & 2 \\
\hline $\mathbf{3}$ & 2 & 3 & 3 & 3 \\
\hline $\mathbf{4}$ & 3 & 4 & 4 & 4 \\
\hline $\mathbf{5}$ & 4 & 9999 & 5 & 5 \\
\hline
\end{tabular}


trata de una zona de planicie. Esto se debe a que, en relación al comportamiento de las aguas, una pendiente muy pronunciada genera una mayor erosión, velocidad y fuerza de las avenidas, lo que le otorga un carácter peligrosidad elevado. Por su parte, los espacios de escasa pendiente impide el discurrir de las aguas, acumulándose y pudiendo provocar auténticos problemas en dichas zonas. Asimismo, conviene tener en cuenta que la Vega Bajase caracteriza por ser una zona de llanura con escasa o nula pendiente, que se traduce en un mayor tiempo de permanencia de las aguas de inundación, ante la falta de drenaje. La combinación entre pendientes muy pronunciadas y zonas de planicies, generan inundaciones en los tramos bajos de los cauces.

En lo referente a la litología (Tabla 2), se les ha otorgado un valor de peligrosidad más elevado a los materiales blandos, al tratarse de los materiales que forman parte de la carga sólida que arrastran las avenidas, así como de los espacios por donde circula la avenida y en donde deposita sus materiales. A ellas se les suma la importancia de incluir los espacios inundables según la cartografía histórica, la peligrosidad geomorfológica, las capas del PATRICOVA y del SNCZI, y la velocidad de las aguas.

Posteriormente, se ha llevado a cabo la unión de los mapas obtenidos con la herramienta SAGA, obteniendo de esta manera el mapa de peligrosidad. Una vez obtenido, se introducido de nuevo en el QGIS y se han sumado los campos de peligrosidad de cada mapa temático. La mayoría de resultados numéricos obtenidos oscilan entre los valores 1-40. Como se ha dicho anteriormente, estos valores cuantitativos han sido transformados en elementos cualitativos, aplicando las cinco categorías definidas. Los valores más bajos corresponden con el resultado total de los valores más bajos de cada capa y viceversa.

Por último, se analizan algunas de las propuestas planteadas por organismos para solventar los problemas de inundación de la rambla de Abanilla, tras el episodio de septiembre de 2019, y que se han ido recogiendo en el denominado Plan Vega Baja Renhace. Asimismo, también se señalan aquellos aspectos negativos que presentan las actuaciones planteadas (Tabla 4). Se recoge, además, en la Tabla 5 , una serie de propuestas que complementarían a las medidas que se tomen para reducir la peligrosidad de la rambla de Abanilla, y que, a su vez, sirven para la adaptación al cambio climático de este territorio.

\section{RESULTADOS}

Los resultados de esta investigación se dividen en tres apartados basados, en el primero de ellos, en el análisis y cartografía histórica, de la cual se ha obtenido un mapa de la red de riegos del tramo final de la rambla de Abanilla en tierras alicantinas. Un segundo apartado basado en los resultados obtenidos tras la modelización del cauce en todo su recorrido por el Bajo Segura. El tercer apartado se centra en los mapas de peligrosidad obtenidos, teniendo en cuenta todos los elementos anteriores. Los tres apartados se suceden en el orden necesario para la obtención final del mapa propio de peligrosidad de inundaciones en el área de estudio. Debe recordarse que tanto la Directiva 60/2007/CE sobre la evaluación y gestión de los riesgos de inundación, y su posterior trasposición a la normativa española en virtud del Real Decreto 903/2010, como la modificación del Reglamento de Dominio Público Hidráulico (Real Decreto 638/2016) y la versión actualizada del PATRICOVA (Decreto 201/2015), señalan la necesidad de incorporar aspectos geomorfológicos e históricos a la hora de la confección de los mapas de inundabilidad. Los primeros (geomorfológicos) están siendo más manejados en la confección de las cartografías de peligrosidad que se elaboran en los últimos años; sin embargo, la incorporación de elementos históricos relacionados con la hidrología, como los sistemas tradicionales de riego que, en ocasiones, actúan como difusores de la inundación en el terreno. De ahí que este trabajo apueste por esta posibilidad para la mejora de la cartografía de peligrosidad de inundaciones, en un área donde estos sistemas tradicionales han tenido una importancia fundamental para el desarrollo agrario y la reducción de la peligrosidad, desde finales de la Edad Moderna hasta la primera mitad del siglo XX.

\section{Cartografía histórica de la rambla de Abanilla.}

Desde la antigüedad los ríos siempre han sido cartografiados por el ser humano al tratarse de un elemento esencial para el desarrollo y actividad de las sociedades. En España, existen planos y mapas de exquisita calidad desde el siglo XVI y, específicamente, del XVIII y XIX (Giménez Font, 2009) que, en ocasiones, explican las casuísticas de muchos de los problemas de la sociedad actual. En el caso de las inundaciones ocurre lo mismo. A pesar de la transformación antrópica de muchos de los territorios, en momentos de precipitaciones copiosas, la naturaleza recupera lo que es suyo y las aguas anegan los espacios por donde tradicionalmente han circulado. 
En el caso de la rambla de Abanilla, gracias a la cartografía histórica, se conoce que presentaba un sistema de boqueras de derivación que captaban las aguas de las crecidas, permitiendo el riego tan deseado en los campos. Asimismo, se contribuía a reducir la escorrentía y evitar el riesgo de inundación en los tramos bajos.

Al tratarse de un cauce con una entidad considerable, los usuarios de sus esporádicas aguas realizaron una cartografía sobre la rambla de Abanilla y su sistema de boqueras en la segunda mitad del siglo XVIII (Fig. 4). El plano muestra hasta tres bifurcaciones que experimenta dicha rambla: la primera tras cruzar el azud de Benferri, con dirección norte-sur hacia la huerta de Orihuela; la segunda desciende por las proximidades de la sierra de Callosa del Segura, dirección norte-sur, hacia el municipio de Redován; y en tercer lugar, al este de la misma sierra, dirección noroeste-sureste hacia Cox.

FIGURA 4.

CARTOGRAFÍA HISTÓRICA SOBRE LA RAMBLA DE ABANILLA Y SU SISTEMA DE BOQUERAS EN LA SEGUNDA MITAD DEL SIGLO XVIII.

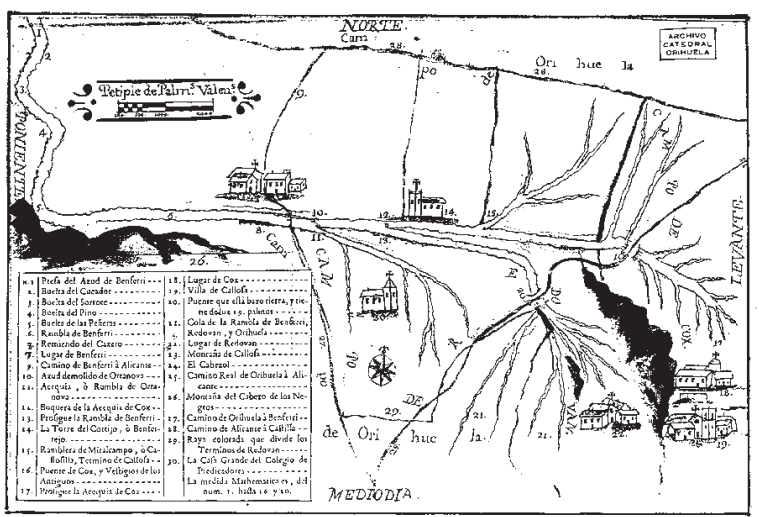

Fuente: Plano extraído de GIMÉNEZ FONT, P., Cartografía histórica y alteración de cursos fluviales en la España mediterránea. En: ALBEROLA, A. OLCINA, J (Eds.). Desastre natural, vida cotidiana y religiosidad popular en la España moderna y contemporánea. Universidad de Alicante, 2009, p. 409.

Por su parte, a finales del siglo XVIII, el ilustrado Cavanilles, en su obra Observaciones sobre la Historia Natural, Geografía, Agricultura, Población y Frutos del Reyno de Valencia, hace alusión a los relieves que destacan desde la sierra de Crevillente, en la cual menciona "Ias Ilamadas de Vilí de Avanilla, y Carche de Jumilla en el reyno de Murcia" (p.257), haciendo referencia a la actual sierra de Abanilla en el sector más oeste de la prolongación de la sierra de Crevillente, en tierras murcianas. En su estancia en Cox indica "Mucha mayor sería si los de Coix lograsen agua para regar las llanuras del Ramblar, suelo apto para todas las producciones, destinados actualmente a granos, por no tener más riego que las lluvias"(p.290). La zona denominada el Ramblar es el espacio comprendido entre la sierra de Orihuela y Callosa, que parte desde Benferri hacia la partida del Escorratel (Orihuela). Tramo que se inunda en las crecidas de la rambla de Abanilla-Redován.

Como se ha podido apreciar, Cavanilles no trata sobre la rambla de Abanilla en su obra, de hecho, en su último capítulo titulado Pías Fundaciones, Huerta y Campo de Orihuela, recoge un croquis sobre el sistema de acequias y azarbes de la Vega Baja del Segura, empero, no tiene en consideración la presencia de la rambla de Abanilla (Fig.5).

\section{FIGURA 5.}

MAPA DE LA HUERTA DE ORIHUELA (1797).

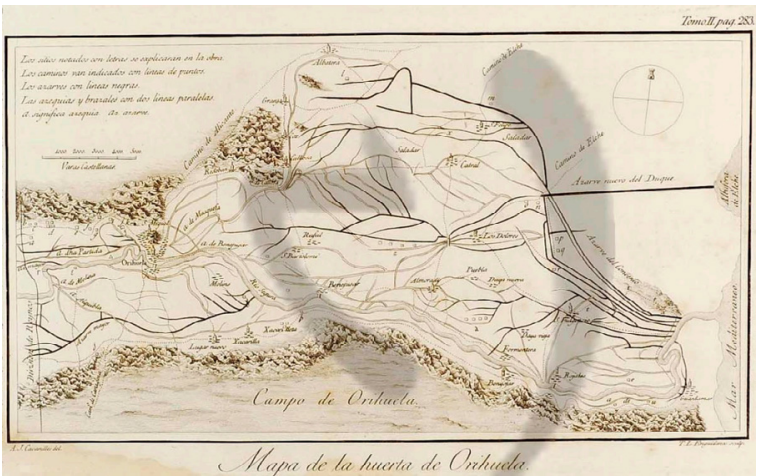

Fuente: Observaciones sobre la Historia Natural, Geografía, Agricultura, Población y Frutos del Reyno de Valencia (1795-1797) por José Antonio Cavanilles, Tomo II, p. 283. Extraído de la Biblioteca Valenciana.

A mediados del siglo XIX (1845-1850), Pascual Madoz en su obra en su obra Diccionario geográfico, estadístico, histórico de España y sus posesiones de Ultramar, se encuentra información sobre la rambla de Abanilla al definir el concepto Abanilla, en la cual se señala lo siguiente:

"Junto á la huerta, á corta dist. De la pobl., pasa de N. á S. una rambla de escasa cantidad de agua, sobrante de la que se emplea en el riego de aquella: proviene en su mayor parte de la sierra del Chícamo, y uniéndose á su corriente la de otra rambla llamada Zurca, que tiene su origen en una balsa en el Algarrobo, y es muy amarga, fertiliza algunos terreno, si bien esta cualidad le es muy perjudicial, a pesar de la union de ambas aguas: el curso de esta última es hácia el S. hasta los confines de la huerta, y desde este sitio se dirige al E. en direccion á Orihuela, aprovechándose de ella los vec. de Menferri". (Madoz, 1845, Tomo I, p. 38-39).

Gracias a esta cartografía, y su comparación con el episodio de inundación de septiembre de 2019 , se 
corrobora la hipótesis que planteaba Giménez Font (2009) que ya relacionaba la presencia del sistema de boqueras y su correspondientes acequias, además de las periódicas inundaciones que, de forma natural, se sufrían en Callosa, Rafal y Dolores, cuando llegaban las aguas de la rambla de Abanilla.

Se trata así de un comportamiento natural, puesto que se verifica la presencia de paleocacues. En efecto, los árabes importaron las técnicas de riego del delta del Nilo, aplicándolo a los abanicos fluviales formados por la rambla de Abanilla, el río Segura, entre otros cauces. Hecho que evidencia la presencia de esta morfología aluvial tan impredecible y peligrosa, puesto que el agua puede circular por cualquier espacio de su abanico, en función de las características de la inundación que acontezca.

Bernabé Gil (1999) analiza las empresas de desecación de zonas lacustres en el Bajo Segura a lo largo del siglo XVII. Uno de los ejemplos paradigmáticos que analiza es el del denominado Pantano de las Fuentes, un humedal de carácter intermitente que durante la década de 1640 se formó en las puertas del recinto de Orihuela.

Esta denominación se debe a la presencia del azarbe de las Fuentes, encargado de recoger las aguas de siete fuentes o manantiales, utilizadas para otras actividades, y dirigirlas hacia el río Segura. A lo largo de esta década se llevan a cabo varios procesos de desecación, sin éxito, ya que en momentos de lluvias frecuentes en invierno aparecía de nuevo este espacio encharcado. En 1643, el Consell oriolano envió a expertos para estudiar la situación, en la cual determinaron que dicha marjal se había formado por las avenidas de la rambla de Abanilla y por haberse dejado de mondar el azarbe de las Fuentes durante varios años consecutivos (Fig. 6).

En síntesis, la empresa para la desecación de dicho humedal se llevó a cabo por Juan de Centellas, por medio de la creación de un canal que dirigiera las aguas hacia el Segura, siendo exitoso dicho proyecto. No obstante, Centellas señala una serie de indicaciones para llevar a cabo una adecuada gestión de

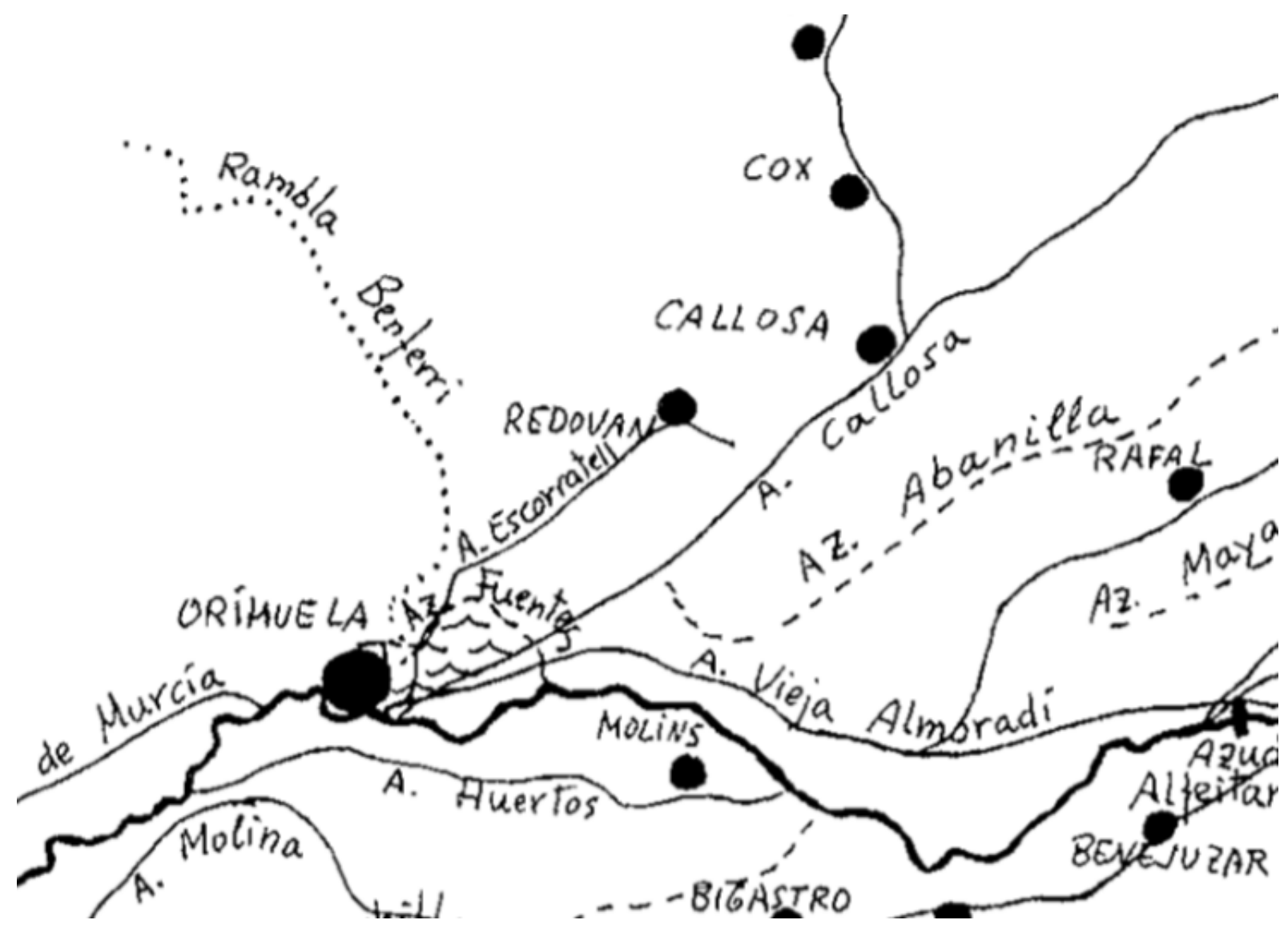

Fuente: Bernabé Gil (1997). Insalubridad y Bonificaciones de almarjales en el Bajo Segura antes de las Pías Fundaciones de Belluga. 
las acequias y azarbes, con el propósito de evitar que esta zona volviera a encharcarse. Desde entonces, dicho espacio lacustre aparecía de manera intermitente durante los siglos posteriores.

A mediados del siglo XIX, Pascual Madoz (1845) señalaba que las aguas que llegaba a este espacio lacustre, además de ser recogidas por el denominado azarbe de las Fuentes, también se recogían por medio de la acequia Mayor, sirviendo para el riego de los cultivos de la huerta, pero que para ello era necesario ser conocedores del territorio y tener conocimientos y prácticas para su correcto uso:

"Luego que el agua principal llega á la huerta, encuentra un partidor que arroja una parte á la acequia Mayor, de donde salen varios ramales que riegan o mas importante de la vega, y el resto va á parar a la acequia de Saqués, que atraviesa la rambla por unos canales de madera, sostenidos por fuertes pilares de piedra sillar: la distribución de estas aguas por horas, llamadas en el país tomas, es de la mayor importancia, y exige conocimientos prácticos" (Madoz, 1845, Tomo I, p. 39).

En última instancia, Francisco de Coellorecogeen su mapa sobre la provincia de Alicante, dentro de sumagnum opus titulado Atlas de España y sus posesiones de Ultramar, el trazado detallado de la rambla de Abanilla. Sin embargo, el tramo dibujado desde Benferri hasta Orihuela, coincide con el de la actualidad, con la única excepción de que se prolonga el cauce de manera definida hasta la partida de El Escorratell. Ello puede implicar que existía un cauce más definido en este espacio y que, con la transformación territorial ha desaparecido, llegando al punto de convertirse en un espacio de circulación de aguas difusas (Fig. 7). En este sentido, la descripción de Madoz tendría lógica al utilizar el azarbe de las Fuentes y la acequia Mayor como infraestructura que recogía las aguas de avenida de la rambla de estudio, a la vez que se evitaba la aparición del Pantano de las Fuentes.

En la actualidad, no existe este espacio lacustre entre el barrio de San Antón y El Escorratel (Orihuela). Empero, en el episodio de inundación en septiembre de 2019, anegó todo este espacio recuperando su función natural de zona pantanosa o lacustre. De ello se puede deducir que la rambla de Abanilla, posee una cuenca endorreica que, en su tramo final y de manera difusa, desembocaría en el denominado Pantano de las Fuentes, que hoy en día corresponde con la pedanía de El Escorratel y el Palmeral de San Antón (Orihuela), ubicación de donde parte el azarbe de las Fuentes hacia el Segura, y la acequia Mayor, entre otros ramales. Asimismo, se encuentra la presencia de un azarbe denominado "azarbe de AbaniIla" que recoge las aguas procedentes de la rambla de Redován(segundo brazal de la rambla de Abanilla, y todo ese espacio conocido como el Ramblar.

La superposición de ambos mapas históricos permite reconstruir la morfología del tramo final de la rambla de Abanilla. El resultado es una cartografía que recoge elementos geomorfológicos donde se observa la presencia de ramblas, paleocauces y abanicos fluviales (Fig. 8). Además, se ha incluido el sistema de boqueras por niveles que actúan como paleocauces pudiendo anegar determinadas zonas. El abandono y la falta de gestión de las boqueras, incrementan los efectos negativos aguas abajo, aunque también es la solución para reducir las inundaciones como se explicará más adelante.

FIGURA 7.

MAPA PROVINCIA DE ALICANTE (1859): CAUCE DE LA RAMBLA DE ABANILLA
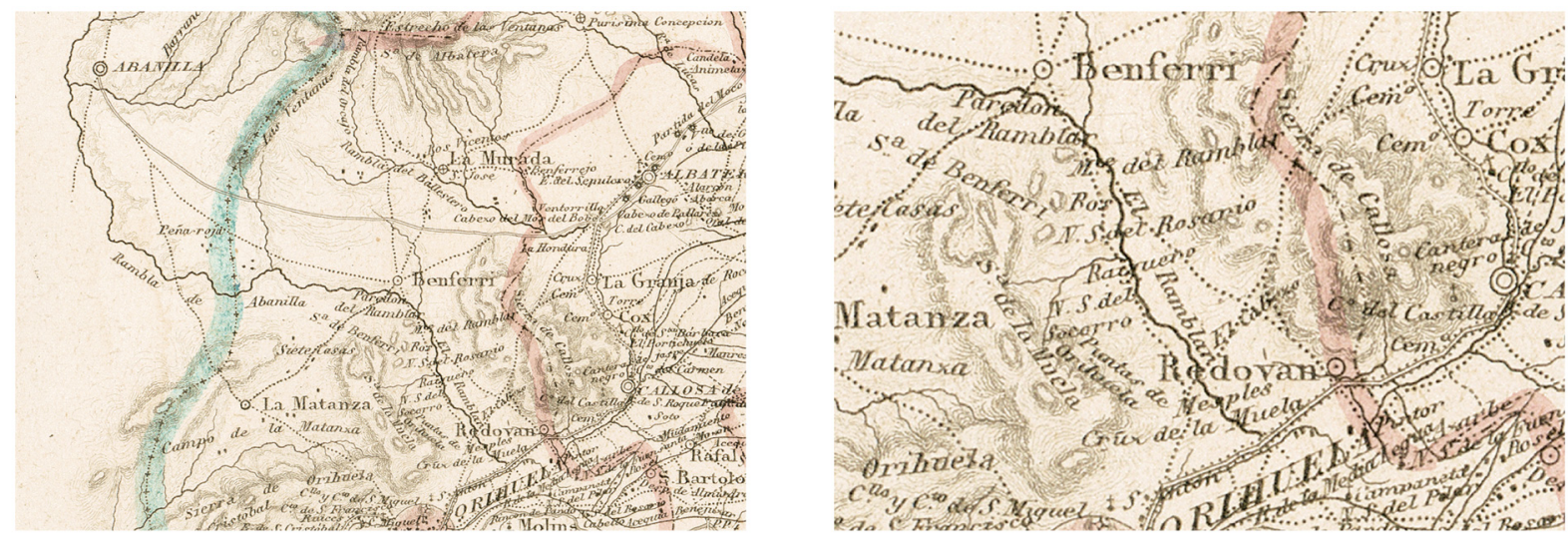

Fuente: Atlas de España y sus posesiones de Ultramar. Francisco Coello (1859). 
FIGURA 8.

ELEMENTOS GEOMORFOLÓGICOS EN LA RAMBLA DE ABANILLA Y SISTEMA DE BOQUERAS.

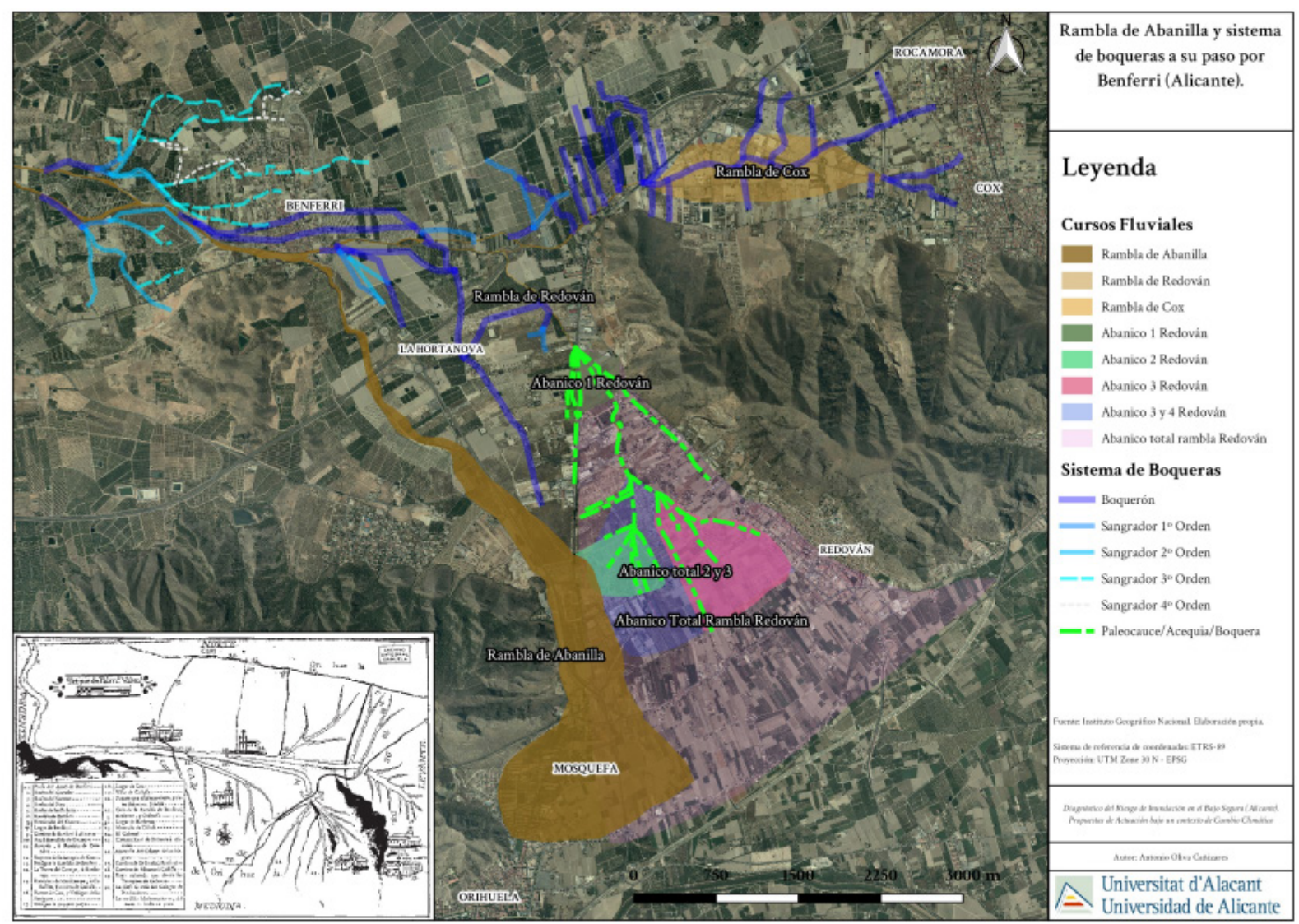

Fuente: Elaboración propia a partir dellnstituto Cartográfico Valenciano (ICV). Fototeca digital. Vuelos de menor superficie y autonómicos. Vuelo Ruiz de Alda. Cuenca Hidrográfica del Segura (1929-1930) y vuelo americano serie B (1956-1957), ha permitido la cartografía de las antiguas boqueras de la rambla de Abanilla.

\section{Modelización de la rambla de Abanilla: peligrosidad y espacios inundables del área de estudio.}

Los resultados obtenidos en la modelización muestran varias zonas conflictivas que ponen en riesgo la vida de las personas. La primera se localiza en la margen izquierda y derecha de la rambla de Abanilla, a la altura del núcleo urbano de Benferri, afectando a la CV-869 (margen izquierda) y el barrio del Cabezo (margen derecha); en la cual la primera se ve afectada con calados entre los 0,10 y $0,60 \mathrm{~m}$, mientras que la segunda presenta calados entre 0,6 y $2 \mathrm{~m}$. Valores que se alcanzan cuando el caudal de la rambla oscila entre los 2 y 4 m (Fig.9).

En efecto, el episodio de inundación de 2019 afectó de manera severa a estos espacios, destruyendo la acera de la CV-869 y una o dos viviendas del barrio del Cabezo, que se encuentran instaladas en el mismo lecho de la rambla. La avenida fue impetuosa debido al volumen de aguas circulante, la carga sólida presente y la fuerza de las aguas, convirtiendo dicha crecida en un peligro severo en los tramos bajos (Fig.10).

El segundo espacio que se ve afectado es la huerta de Orihuela, ubicada entre la sierra del mismo nombre y Callosa. La modelización muestra que la escorrentía difusa anegaría, en primer lugar, el polígono industrial de Puente Alto con calados de 0,5 a 1,90 m, lo que supone un riesgo grave para las vidas humanas, actividades económica allí implantadas y severos daños materiales.

A continuación, aguas abajo, se ve afectado por completo el aparcamiento del concesionario ubicado entre la N-340 y la CV-930, con una altura de las aguas entre 1 y $2 \mathrm{~m}$. Asimismo, el polígono industrial, al norte del Escorratel, presenta calados que oscilan entre los 0 y 1,5 $\mathrm{m}$ de altura. La pedanía de El Escorratel también se vería afectada por las aguas casi en su tramo final de trayecto de las aguas, presentando una altura entre 0,5 y $0,9 \mathrm{~m}$ (Fig. 11). 
FIGURA 9

RESULTADOS DE LA MODELIZACIÓN (CALADO) EN LA RAMBLA DE ABANILLA A LA ALTURA DE BENFERRI

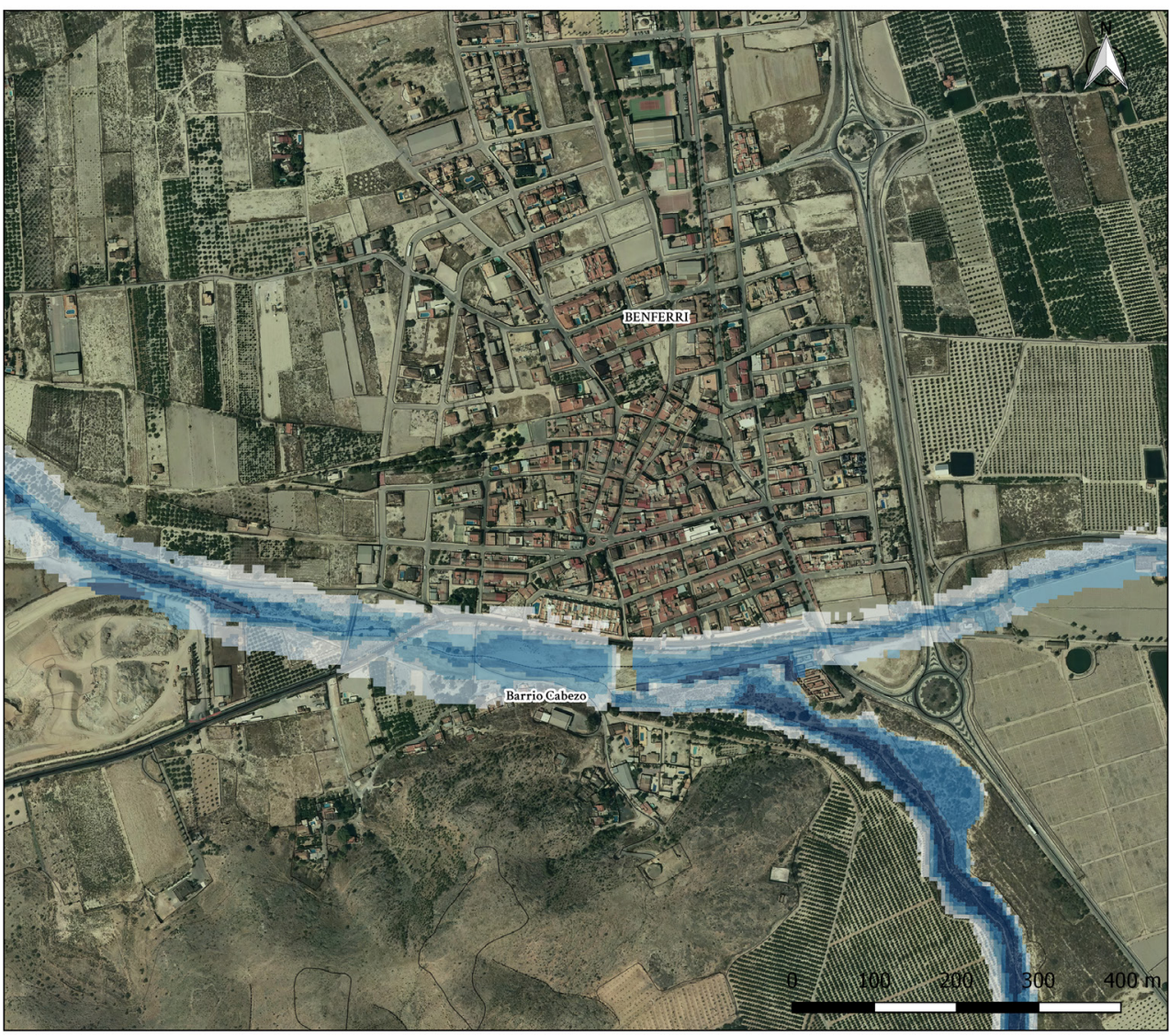

Mapa de calados en

Benferri resultado

de la modelización

con HEC-RAS

Leyenda

$4.2000-5.0000$

$3.4000-4.2000$

$2.6000-3.4000$

$1.8000-2.6000$

$1.0000-1.8000$

Fuente: Elaboración propia a partir del tratamiento de módulos de cartografía de HEC-RAS v.5.0.6.

FIGURA 10.

EFECTOS DE LA AVENIDA DE LA RAMBLA DE ABANILLA EN BENFERRI.
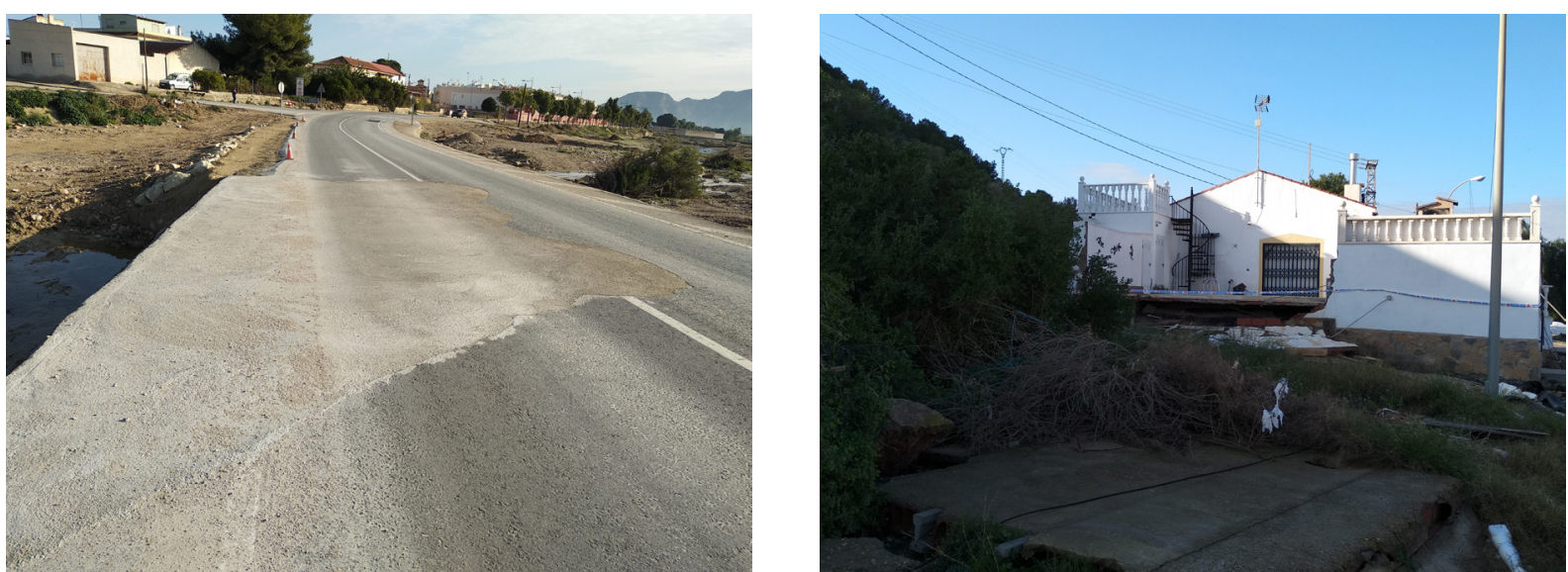

Fuente: Como se aprecia en la imagen una parte de la CV-869 quedó destrozada ante la impetuosa avenida, en la cual en los tres meses siguiente habían conseguido reparar la rotura. Además, se observa los efectos destructores de la avenida en la vivienda que se encuentra inmersa en el lecho de la rambla, la cual quedó totalmente destrozada en su exterior e interior. Fotografía realizada por Antonio Oliva Cañizares (06/12/2019). 
FIGURA 11.

RESULTADOS DE LA MODELIZACIÓN (CALADO) EN LA RAMBLA DE ABANILLA A LA ALTURA PUENTE ALTO

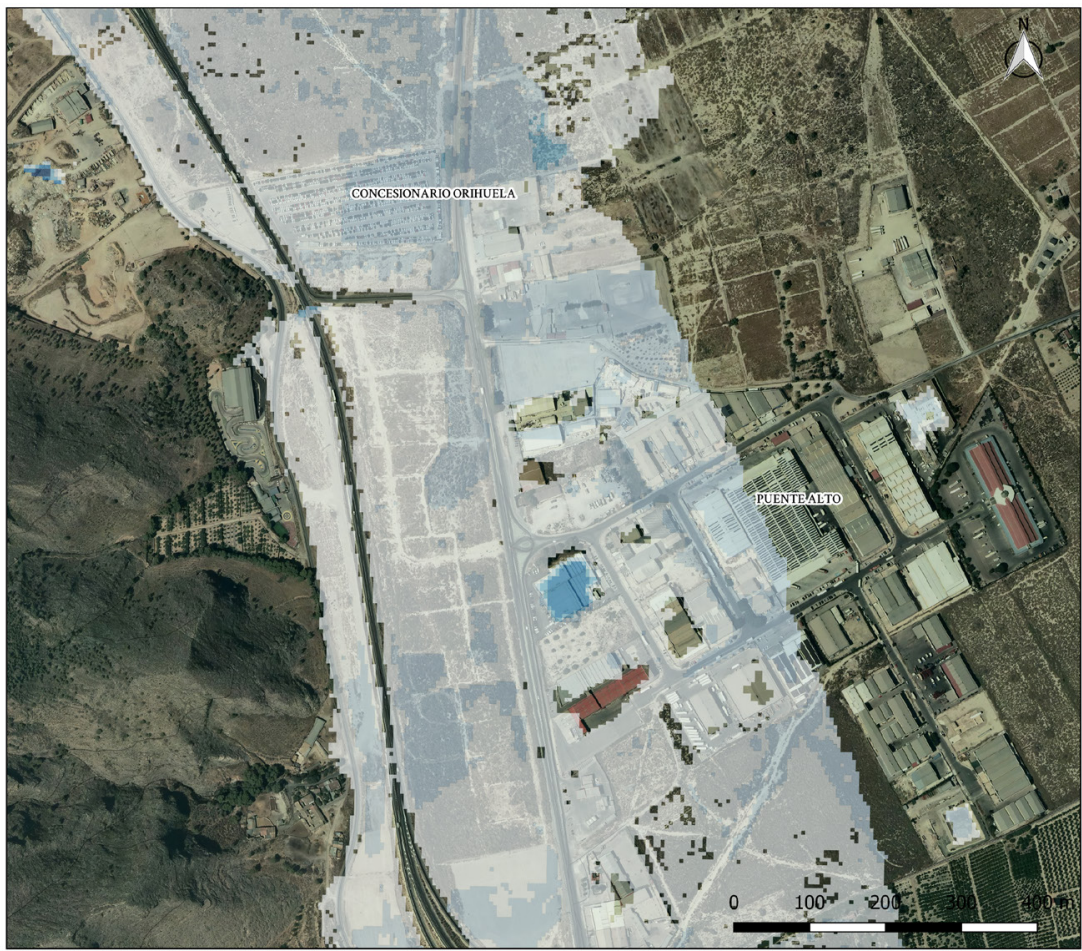

Mapa de calados en

Puente Alto

resultado de la

modelización con

HEC-RAS

Leyenda

$4.2000-5.0000$

$3.4000-4.2000$

$2.6000-3.4000$

$1.8000-2.6000$

$1.0000-1.8000$

Fuente: Elaboración propia a partir del tratamiento de módulos de cartografía de HEC-RAS v.5.0.6.

FIGURA 12.

RESULTADOS DE LA MODELIZACIÓN (CALADO) EN LA RAMBLA DE ABANILLA A LA ALTURA DEL PALMERAL DE SAN ANTÓN.

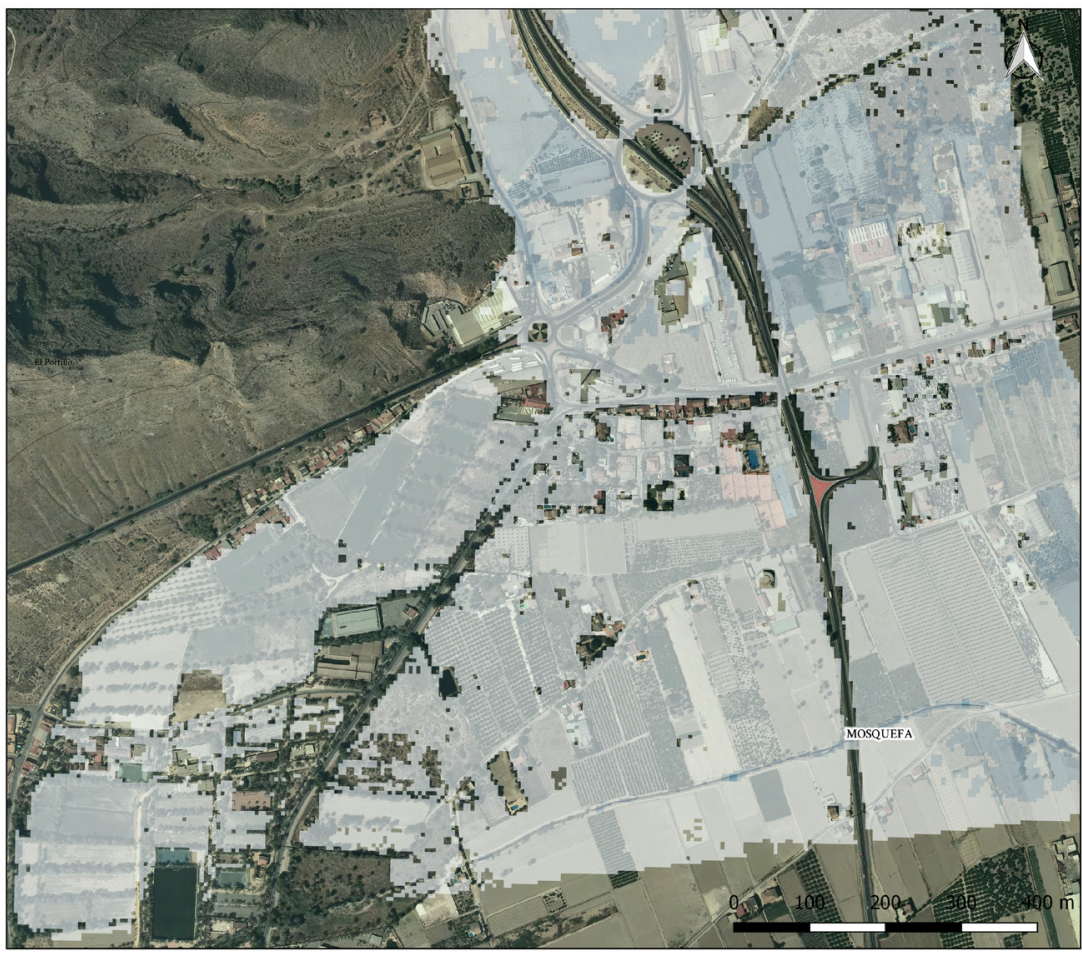

Mapa de calados en el Palemeral de San

Antón resultado de

la modelización con

HEC-RAS

Leyenda

$4.2000-5.0000$

$3.4000-4.2000$

$2.6000-3.4000$

$1.8000-2.6000$

$1.0000-1.8000$

Fuente: Elaboración propia a partir del tratamiento de módulos de cartografía de HEC-RAS v.5.0.6. 
Aguas abajo, desde el barrio de San Antón hasta la carretera CV-930 (Fig.12), también se ven afectadas, puesto que es el fin de la rambla de Abanilla, donde se acumulan las aguas. Este espacio presenta calados entre 0,1 y 0,5 m. Conviene recordar que todo este sector corresponde con el antiguo Pantano de las Fuentes que, hoy en día, se encuentra ocupado por colegios, institutos, el Palmeral de San Antón y algunas viviendas, que se encuentran ubicadas en un espacio inundables y donde el riesgo es elevado. Los resultados mostrados reflejan las zonas anegadas en el episodio de septiembre que tuvo consecuencias económicas severas, a causa de la presencia de todas las instalaciones mencionadas anteriormente (Fig. 12).

La tercera zona se corresponde con la denominada rambla de Redován, en la cual la modelización muestra la configuración de un gran abanico fluvial desde tierras de Redován hasta el azarbe de Abanilla (Fig. 13). Estas unidades geomorfológicas se caracterizan por una escorrentía difusa del agua, en todo su abanico, una escorrentía concentrada en cauces y paleo- cauces, que dirigen sus aguas a las zonas más bajas, anegando el polígono industrial de Puente Alto y el sector más bajo del núcleo urbano de Redován.

El calado que se dirige hacia el polígono industrial presenta valores que oscilan entre 0-1 m; mientras que en Redován se encuentra en un intervalo entre 0-1,10 m. Asimismo, los espacios vacíos de la modelización no sugieren que no exista peligrosidad, sino que en su cálculo han salido los resultados reflejados. Sin embargo, se debe considerar que todo el abanico quedaría anegado y que es una zona con una peligrosidad severa. En lo referente a las zonas urbanas que se encuentran afectados o no por la modelización, deben tenerse en cuenta como lugares con un elevado riesgo de inundación, que no solo depara daños económicos, sino también sociales. De hecho, en el episodio de septiembre de 2019, un hombre de Redován pierde su vida por el arrastre de las aguas.

Por tanto, se tratan de espacios que presentan problemas de inundación importantes, que afectan a un

FIGURA 13.

RESULTADOS DE LA MODELIZACIÓN (CALADO) EN LA RAMBLA DE ABANILLA-REDOVÁN A LA ALTURA DEL MUNICIPIO DE REDOVÁN.

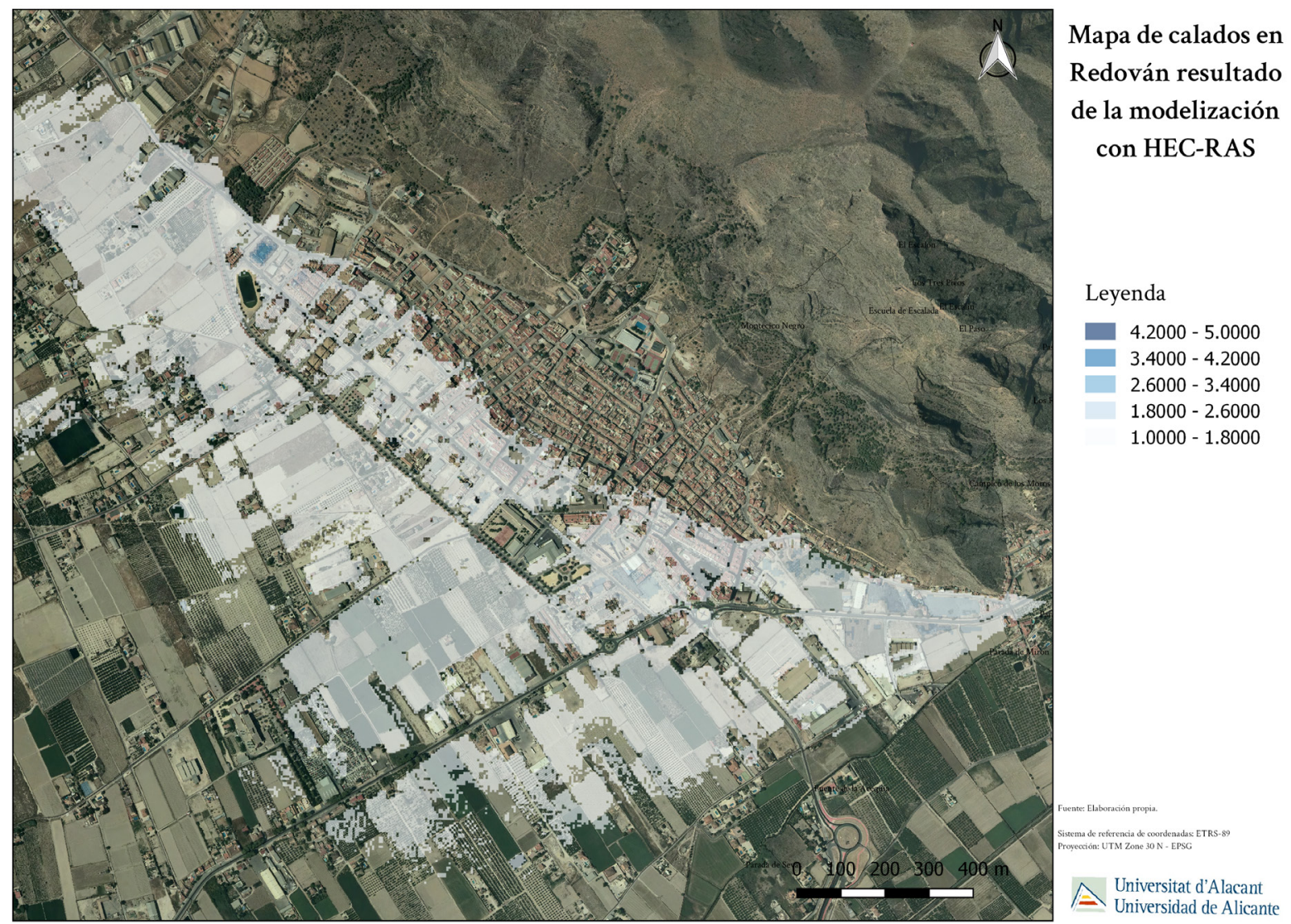

Fuente: Elaboración propia a partir del tratamiento de módulos de cartografía de HEC-RAS v.5.0.6. 
gran número de personas, y que urge la toma de medidas que permitan reducir o paliar los efectos negativos de las inundaciones.

\section{Cartografía de peligrosidad de inundación por la rambla de Abanilla.}

La cartografía de peligrosidad de inundación en los tramos de la rambla de Abanilla, son el resultado de la suma de los mapas temáticos señalados en la metodología. Se han escogido las cinco zonas analizadas anteriormente en la modelización T(500), correspondientes con Benferri, barrio de Cabezo (Benferri), el polígono industrial de Puente Alto, la zona del Palmeral de San Antón y Redován.

Como se observa en el primer mapa (Fig. 14), la rambla de Abanilla presenta una peligrosidad "Muy Alta" en el centro del lecho, que afecta a la carretera CV-869 (en el lecho y su margen izquierda), y alguna de las viviendas situadas en el margen derecho, en el barrio del Cabezo. Asimismo, el núcleo urbano de Benferri y parte del barrio del Cabezo, presentan una peligrosidad "Me- dia". El primero, por desbordamiento de la rambla de Abanilla y las aguas que descienden desde la sierra de Abanilla-Crevillente, y de las numerosas lomas al norte de la localidad. El segundo se debe a los barrancos que descienden de los relieves del sur del barrio, así como la presencia de una rambla afluente de la propia Abanilla. Como se ha mencionado en reiteradas ocasiones, dichas zonas se vieron gravemente afectadas por el episodio de septiembre de 2019.

La segunda zona corresponde con el tramo en el cual la rambla de Abanilla deja de tener una presencia encajada y cuyas aguas comienzan a circular de manera difusa, anegando todos los espacios que se encuentran en su recorrido. Este es el caso, como ya se ha visto en la modelización, del polígono industrial de Puente Alto y el aparcamiento de uno de los concesionarios del mismo sector. La Figura 10 muestra de manera esclarecedora que, todo este espacio, de media, tiene una peligrosidad de inundación "Muy Alta" y "Alta", siendo las zonas más susceptibles de verse afectadas las zonas mencionadas anteriormente (Fig. 15).

FIGURA 14.

CARTOGRAFÍA DE PELIGROSIDAD DE INUNDACIÓN EN BENFERRI (ALICANTE).

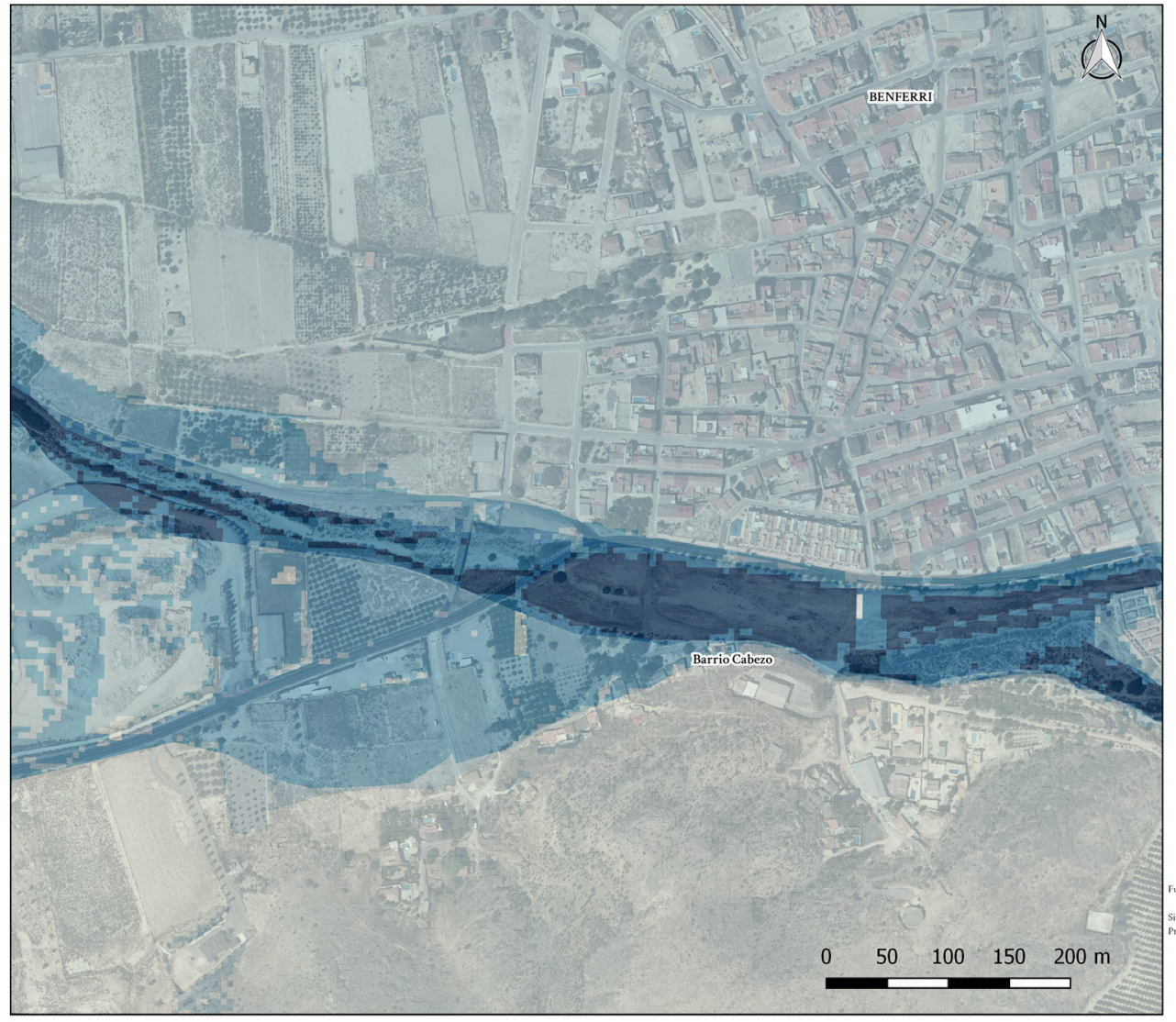

Peligrosidad por

inundación en

Benferri (Alicante).

Leyenda

Muy Alta

Alta

Media

Baja

Muy Baja

Elaboración propia. 
FIGURA 15.

CARTOGRAFÍA DE PELIGROSIDAD DE INUNDACIÓN EN PUENTE ALTO EN ORIHUELA (ALICANTE).

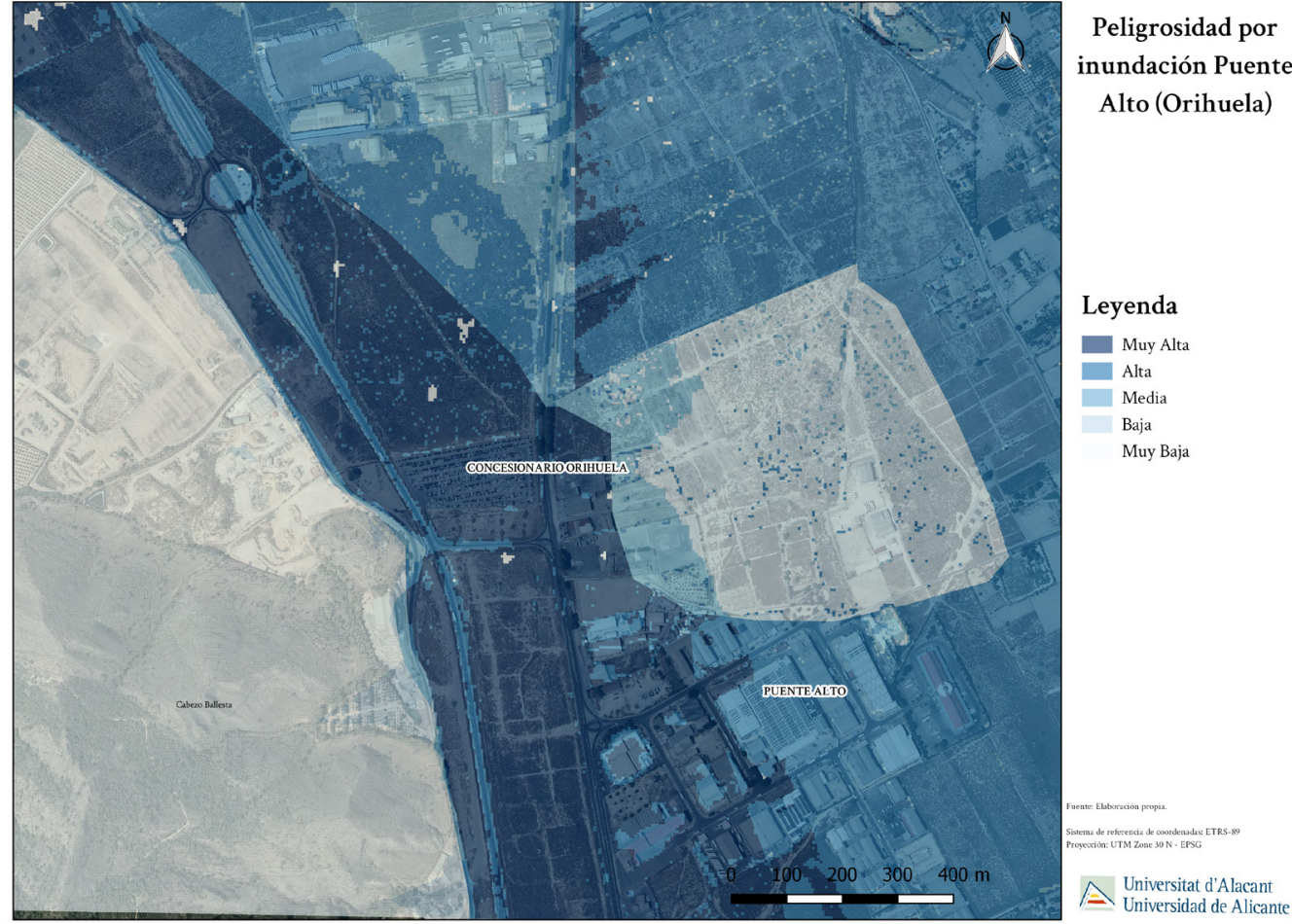

Elaboración propia.

FIGURA 16.

CARTOGRAFÍA DE PELIGROSIDAD DE INUNDACIÓN EN LA PEDANÍA DEL ESCORRATEL (ORIHUELA).

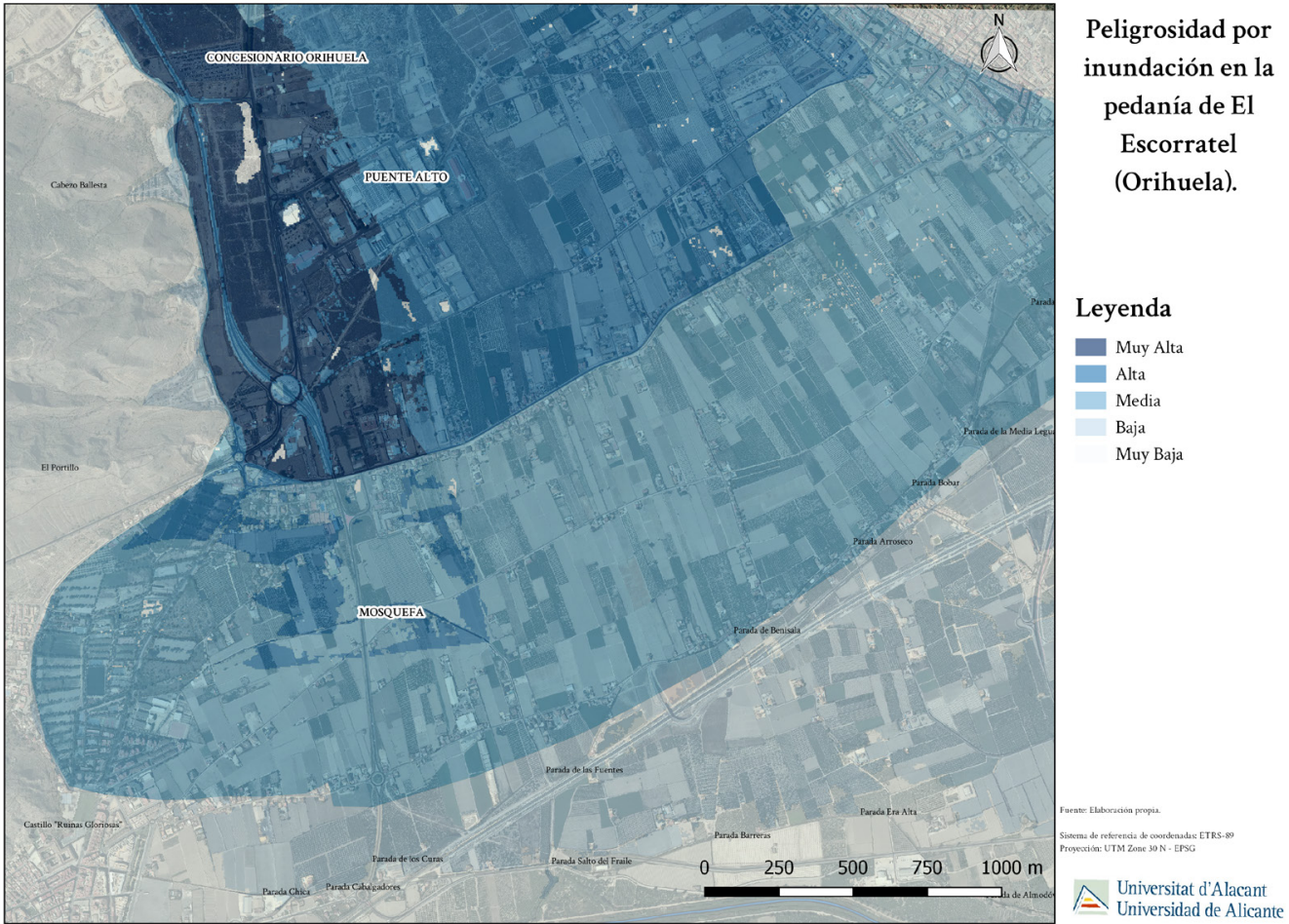

Elaboración propia. 
La tercera zona hace referencia a la antigua zona endorreica del Pantano de las Fuentes, donde se encuentra actualmente, la pedanía de El Escorratel y el palmeral de San Antón, pertenecientes a Orihuela (Fig. 16). Como se observa en la Figura 16, el sector de Puente Alto sigue presentando una peligrosidad "Muy Alta". Aguas abajo, en dicha pedanía, la peligrosidad es "Alta" y "Media", y en las proximidades del Segura "Baja". Esto se debe a que la avenida aún posee la suficiente fuerza como para llegar a este punto. Seguramente, las aguas invadirían todo este sector, desde el Segura hasta el Escorratel, recuperando su función y dinámica natural de un espacio lacustre.

Por último, la cuarta zona corresponde con el término municipal de Redován, el cual presenta una peligrosidad "Alta" motivada por la presencia de la rambla de Redován (continuación de rambla de Abanilla) (Fig. 17). Prácticamente, todas las viviendas que se encuentran en la margen izquierda de dicha rambla, que coincide con el sector más bajo del núcleo urbano, se verían afectadas en por la avenida. Como se ha dicho anteriormente, este municipio quedó anegado y un hombre perdió la vida al ser arrastrado por la corriente de agua. Ello se debe a que en este sector, coinciden la confluencia de las aguas descendientes de las torrenteras de la sierra de Callosa del Segura que descienden por las calles del sector más elevado del municipio hasta la zona más profunda; y en este sector, se unirían con las aguas de avenida de la rambla de Redován.

Todos los espacios analizados presentan una elevada peligrosidad que, como se ha observado, afecta a una gran multiplicidad de infraestructuras y construcciones humanas (viviendas, polígonos, aparcamientos, etc.), que se traducen en una elevada vulnerabilidad; y el producto de ambos, daría como resultado un espacio con un riesgo de inundación muy importante. En efecto, estas carencias y vulnerabilidades, se dejaron sentir en el episodio de septiembre de 2019.

En este sentido, se ha calculado las hectáreas por usos de las superficies edificadas de los municipios que se verían afectados en caso de un episodio de inundación (Tabla 3). En ella se observa que el suelo más predominante en las zonas inundables corresponde con las zonas residenciales.

FIGURA 17.

CARTOGRAFÍA DE PELIGROSIDAD DE INUNDACIÓN EN EL TÉRMINO MUNICIPAL DE REDOVÁN (ALICANTE).

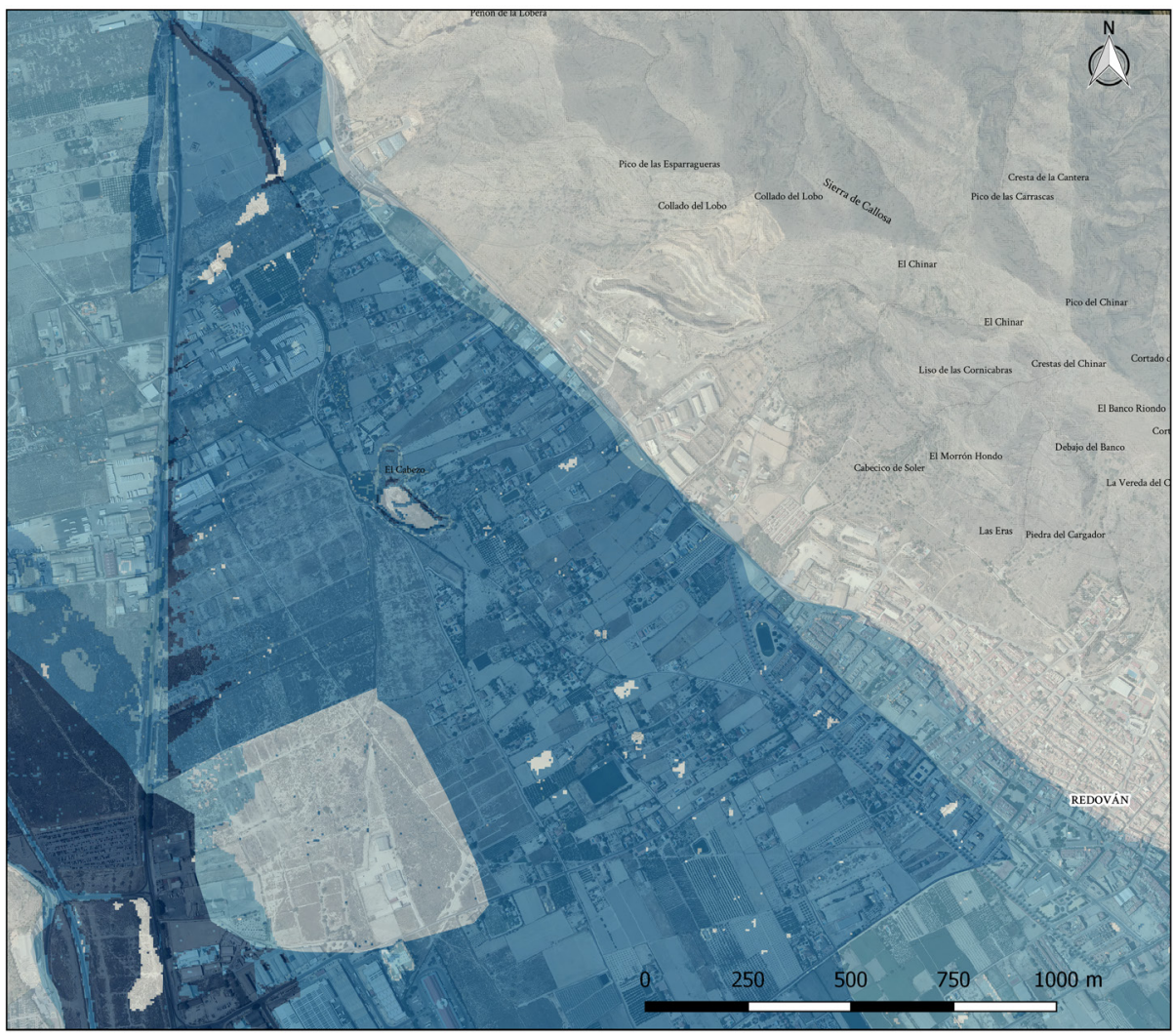

Peligrosidad por inundación en Redován (Alicante).

Elaboración propia. 
TABLA 3.

SUPERFICIES CONSTRUIDAS EN ZONAS INUNDABLES DE LA RAMBLA DE ABANILLA.

\begin{tabular}{|c|c|c|c|c|c|}
\hline Municipios/Usos & Residencial (Ha.) & Industrial (Ha.) & Agrario*(Ha.) & Equipamientos (Ha.) & $\begin{array}{c}\text { Sup. Edificadas en Zl por municipios } \\
\text { (Ha.) }\end{array}$ \\
\hline Benferri & 16,3 & 0 & 1,7 & 0,64 & 18,64 \\
\hline Orihuela & 22,87 & 26,37 & 1,60 & 2,85 & 53,69 \\
\hline Redován & 22,91 & 9,23 & 1,04 & 1,95 & 35,13 \\
\hline Cox & 25,15 & 17,91 & 1,88 & 0,08 & 45,02 \\
\hline & & & & & 152,48 \\
\hline Total Sup. Usos & 87,23 & 53,51 & 6,22 & 5,52 & \\
\hline & & & & & $4.219,3$ \\
\hline Área total inundable & & & & & \\
\hline
\end{tabular}

*Las hectáreas afectadas de suelo agrario hacen referencia, exclusivamente, a las edificaciones que se encuentran en las haciendas. No incluye la superficie agraria de las propias haciendas. Fuente: Instituto Cartográfico Valenciano (ICV). Elaboración propia.

Por tanto, de una superficie de $4.219,3$ Ha de zonas inundables, 152,48 corresponden a las construcciones antrópicas de uso residencial, industrial, agrario y equipamientos; lo que implica que la diferencia entre éstos y el área inundable, generalmente, pertenecerán a los campos de cultivos.

\section{DISCUSIÓN}

Los resultados presentados en este trabajo han permitido resolver los cuatro objetivos establecidos en la presente investigación (ver Introducción). Se ha elaborado una cartografía propia de peligrosidad de la rambla de Abanilla (objetivo 1). No obstante, teniendo en cuenta la cartografía histórica, la rambla de Abanilla presentaba tres grandes ramales en la cual derivaban sus aguas hacia Orihuela, Redován y Cox, siendo imposible llevar a cabo la modelización del antiguo tramo de Cox, puesto que hoy en día ha desaparecido o se encuentra soterrado por la presencia de infraestructuras. Este es el motivo por el cual no se ha obtenido un mapa de peligrosidad de este sector, aunque de realizarse presentaría valores de peligrosidad "Alta" o "Muy Alta" en función de los resultados obtenidos en sectores próximos del curso actual. No obstante, Soriano (2004) indica que Cox se ve afectada por las aguas de crecida de la rambla de Abanilla. En definitiva, los mapas de peligrosidad sientan las bases para ser complementados con una cartografía de vulnerabilidad, incorporando los usos del suelo actuales y la población instalada, para obtener una cartografía de riesgo actualizada y de riguroso carácter científico.

Por su parte, la comparativa entre los resultados obtenidos y las cartografías oficiales (objetivo 2), se considera la cartografía obtenida es mucho más completa y detallada que las del SNCZI y el PATRICOVA. Ello se debe a varios motivos: el primero es que se trata de un estudio actualizado que ha incorporado diferentes cuestiones interrelacionadas con las inundaciones como la pendiente y la litología, entre la serie de mapas temáticos señalados en la metodología. En segundo lugar, se ha realizado una modelización teniendo en cuenta los efectos del último episodio ocurrido en septiembre de 2019 y los resultados son prácticamente idénticos a los espacios afectados en dicho evento, para el que se calcula un periodo de retorno entre 2550 años, en comparación con las zonas afectadas que ofrecen las cartografías oficiales.

Otro de los motivos se debe a que la cartografía obtenida está realizada a una escala de detalle municipal, convirtiéndose así en un documento referente a efectos de planificación territorial y asignación futura de nuevos usos de suelo para los municipios afectados. Asimismo, aparecen nuevos espacios que presentan peligrosidad de inundación que, de manera individual, no lo señala ni el SNCZI ni el PATRICOVA. Además, los datos de calados obtenidos pueden utilizarse para un futuro estudio relacionado con la vulnerabilidad de los municipios en función de los calados. También se sugiere tener en cuenta como un elemento de peligrosidad alto los calados de más de $0,20 \mathrm{~m}$, que según la fuerza de las aguas, es capaz de arrastrar a una persona. Lo mismo ocurre con el valor 0,50 $\mathrm{m}$, en el cual los coches comienzan a flotar y ser arrastrados por el agua. Estas cuestiones deben considerarse y atenderse en mayor medida, en vez de los $0,80 \mathrm{~m}$ que establece el PATRICOVA. Por último, el dato de calado obtenido teniéndose en cuenta el Modelo Digital del Terreno, ofrece un valor determinado según el espacio que se quiere consultar y no de manera genérica como las cartografías oficiales. Elemento que se traduce no sólo en un mayor o menor 
grado de peligrosidad, sino que también determinan el grado de vulnerabilidad y, asimismo, el riesgo real de inundación ante un evento de las características introducidas (objetivo 3).

Respecto a la modelización, como se ha mencionado en la metodología, al no existir estaciones de aforo que registren los caudales en los cursos esporádicos, la modelización ha sido realizada con un caudal desde Murcia-Benferri-Orihuela de $600 \mathrm{~m}^{3} / \mathrm{s}$ y desde Benferri-Redován de $200 \mathrm{~m}^{3} / \mathrm{s}$. Evidentemente, el primero resulta una cifra un tanto exagerada pero conviene señalar que se ajusta a las zonas afectadas del episodio analizado. Asimismo, permite conocer aquellas zonas que se verían anegadas aunque el programa parece ser que no termina de calcular bien las zonas inundables puesto que generan inundaciones de manera aislada, cuando el territorio comparte las mismas características en pocos metros de distancia. Además, Soriano (2004) señala que al desviarse el caudal de la rambla de la Abanilla por los azarbes para riego, aguas debajo de Redován, generan inundaciones en Almoradí y Dolores. Es por ello que estas cuestiones no restan valor a los resultados obtenidos, sino que más bien debe servir como alarma de aquellas zonas que se verán afectadas con un caudal similar entre el real y el introducido en la modelización.

Se debe destacar que el aviso rojo decretado por la Agencia Estatal de Meteorología (AEMET), 24 horas antes del episodio de lluvia torrencial de septiembre de 2019, permitió salvar muchas vidas humanas en la comarca del Bajo Segura. Sobre todo, la vida de los más jóvenes al cancelarse las clases, ya que de no haber sido así, hubiera habido muchas más víctimas y problemas. Asimismo, este episodio ha permitido identificar varias carencias respecto a la cultura de inundaciones en la Vega Baja.

Una carencia importante detectada es la ausencia de Planes de Emergencia en los municipios del Bajo Segura. Durante el episodio de inundación, las administraciones y particulares no sabían de qué manera afrontar el episodio de tal envergadura, lo que se tradujo en un caos tanto para los equipos de emergencia como para los afectados. Esto se debe a que la Ley que rige la elaboración de los planes de emergencia a nivel municipal, no exige la obligatoriedad de la redacción de uno en aquellos municipios que tienen menos de 2.000 habitantes. Esto es un graso error, todos los municipios deben contar con un plan de emergencia para afrontar cualquier amenaza natural o tecnológica que pueda existir. En el caso de los cuatro núcleos de población citados en el presente trabajo (Benferri,
Cox, Orihuela y Redován), solamente Orihuela posee un Plan de Emergencia Municipal, en la cual menciona a Benferri en tres ocasiones, pero no presenta unas directrices de actuación o de gestión de las inundaciones, sino que se señala como zona de elevada peligrosidad. Estas cuestiones deben tenerse en cuenta en la escala local, sean municipios, pueblos, pedanías, etc., puesto que cada zona debe actuar de una manera en función de cómo se comporte el agua en estos espacios. Para ello, se apuesta por la cartografía de riesgos naturales, obligada por ley, y que sientan las bases de la elaboración de los planes de emergencia a escala local. La suma de todos los planes de emergencia locales, permitirán llevar a cabo la elaboración de un Plan de Emergencias Regional para cualquier ámbito.

Por su parte, ante la elevada peligrosidad que presenta la rambla de Abanilla, no extraña que se hayan realizado propuestas para intentar solventar los problemas de inundación que genera en su tramo final (objetivo 4). Algunas de las propuestas planteadas se basaban en encauzar la rambla de Abanilla en algunos tramos, al tiempo que se procede a la restauración ecológica y a la reforestación de parte de su cabecera (en coordinación con Murcia), contribuyendo así eficazmente a frenar la erosión y los arrastres, para así evitar que la onda de crecida se dirija a la huerta hoy totalmente ocupada lo que viene siendo contraproducente (Soriano, 2004).

Otro propuesta más radical y costosa que recoge el autor es desviar la rambla de Abanilla hasta el Embalse de Santomera mediante un encauzamiento, que debería tener, al menos, una capacidad de $150 \mathrm{~m}^{3} / \mathrm{s}$, así como una longitud aproximada de 8 kilómetros, pero que ya es una obra recogida en el Plan Hidrológico de Cuenca del Segura y el PATRICOVA, a la que se le concede una prioridad alta y cuyo coste asciende a 12,62 millones de euros (Soriano, 2004). Esta medida ya se planteó en el episodio de inundación de septiembre de 1966 y la CHS reitera esta propuesta en abril de 1967, tras otro episodio de inundación provocado por la rambla de Abanilla. A partir de esta fecha ya no se vuelve a hablar sobre esta medida, ya que adquieren mayor relevancia las inundaciones provocadas por el río Segura desde los años setenta en adelante.

Asimismo, en esta misma línea, se propone desviar las aguas de la rambla de Abanilla al río Segura, siendo el proyecto más costoso ya que atravesaría la huerta y las indemnizaciones de la obra la haría muy onerosa, siendo menos funcional y más complicada que las dos anteriores, considerando la primera como la más coherente y lógica (Soriano, 2004). 
Con el episodio de lluvias torrenciales de septiembre de 2019 y ante las consecuencias catastróficas de las inundaciones acaecidas, la Generalitat Valenciana se abarca en un ambicioso plan denominado Plan Vega Baja Renhace. Dicho plan pretende recoger una serie de valoraciones y propuestas por expertos y los residentes de la Vega Baja, conocedores del territorio, para plantear posibles soluciones que se incluyan en dicho plan y tramitarlas a la Generalitat Valenciana que, en última instancia decidirá qué proyectos abordar. Las propuestas recogidas en dicho Plan se recogen en la Tabla 4 y Figura 18.

Estas propuestas que se plantean se basan en obras estructurales cuyo objetivo es darle una rápida salida a las aguas de avenida para reducir la peligrosidad. Estas medidas quedan obsoletas frente a la visión y en el contexto de las subvenciones de los fondos europeos. Además, una de las propuestas planteadas por La
Generalitat es la de crear un centro de investigación mundial sobre inundaciones en la comarca, con sede en Orihuela, y que cuya finalidad se dirija en la búsqueda de soluciones a problemas de inundación con medidas alternativas que cumplan con los objetivos establecidos en la Directiva 60/2007/CE sobre la evaluación y gestión del riesgo de inundaciones. Medidas que no se contemplan en las propuestas analizadas del Plan Vega Baja Renhace.

Independientemente de los costes de las obras, realizando un análisis de las propuestas planteadas hasta la fecha se pueden calificar como irracionales. Para analizar estas propuestas se procede a realizar una serie de consideraciones/valoraciones del porqué cualquier actuación que se lleve a cabo en este curso fluvial, de comportamiento torrencial, debe estudiarse con detalle analizando aspectos ambientales y económicos favorables y desfavorables:

TABLA 4

PROPUESTAS RECOGIDAS EN EL PLAN VEGA BAJA RENHACE PARA LA RAMBLA DE ABANILLA.

\begin{tabular}{|c|c|c|}
\hline Propuesta & Descripción & Aspectos negativos observados según la propuesta \\
\hline $\begin{array}{l}\text { Solución Norte } \\
\text { (Segura } \\
\text { Transparente) }\end{array}$ & $\begin{array}{l}\text { Encauzar la rambla de Abanilla } \\
\text { por el norte de la sierra de } \\
\text { Callosa, al azarbe del Convenio } \\
\text { y de ahí al Parque Natural de } \\
\text { El Hondo. }\end{array}$ & $\begin{array}{l}\text { Creación de nuevas zonas inundables. } \\
\text { Incapacidad de los azarbes para soportar las aguas de avenida de la rambla de Abanilla. } \\
\text { En caso de realizarse, los posibles contaminantes a lo largo del canal afectarían al ecosistema del } \\
\text { Parque Natural del Hondo o Salinas de Santa Pola. } \\
\text { Coste de la obra muy elevado. } \\
\text { Nulo aprovechamiento de las aguas pluviales. } \\
\text { Pérdida del valor de las aguas por la salinización de las mismas. } \\
\text { Falta de adaptación al cambio climático. }\end{array}$ \\
\hline $\begin{array}{l}\text { Solución Centro } \\
\text { (Demarcación } \\
\text { Hidrográfica del } \\
\text { Segura, DHS) }\end{array}$ & $\begin{array}{l}\text { Encauzar la rambla de Abanilla } \\
\text { haciéndola desaguar en el } \\
\text { cauce nuevo del río Segura. }\end{array}$ & $\begin{array}{l}\text { Creación de nuevas zonas inundables. } \\
\text { En caso de llevarse a cabo, los posibles contaminantes a lo largo afectarán a las aguas que circulan } \\
\text { por el río Segura. } \\
\text { El actual encauzamiento del río Segura es incapaz de soportar sus propias crecidas como para } \\
\text { recibir las aguas de la rambla de Abanilla. } \\
\text { Potencia el riesgo de inundación aguas abajo. } \\
\text { Coste de la obra muy elevado. } \\
\text { Nulo aprovechamiento de las aguas pluviales. } \\
\text { Falta de adaptación al cambio climático. }\end{array}$ \\
\hline $\begin{array}{l}\begin{array}{l}\text { Solución Sur } \\
\text { (Posibilidad A) }\end{array} \\
\text { (Segura } \\
\text { Transparente) }\end{array}$ & $\begin{array}{l}\text { Encauzar la rambla de Abanilla } \\
\text { y derivarla por los azarbes } \\
\text { entre del sector de Redován y } \\
\text { Almoradí, con dirección hacia la } \\
\text { desembocadura en Guardamar } \\
\text { del Segura. }\end{array}$ & $\begin{array}{l}\text { En la inundación de noviembre de 1987, el azarbe de Abanilla se desbordó por las aguas recibidas } \\
\text { de la rambla de Abanilla, además de la propia lluvia, anegando El Saladar (Almoradí), el barrio de la } \\
\text { Estación, el cementerio de Dolores y parte de esta población, que unida a las agua desbordadas del } \\
\text { Segura, convirtió los alrededores de Almoradí en una auténtica balsa. } \\
\text { Creación de nuevas zonas inundables. } \\
\text { Incapacidad de los azarbes para soportar las aguas de avenida de la rambla de Abanilla. } \\
\text { Posible contaminación de las aguas circulantes por los azarbes. } \\
\text { Potencia el riesgo de inundación aguas abajo. } \\
\text { Coste de la obra muy elevado. } \\
\text { Nulo aprovechamiento de las aguas pluviales si acaban anegando las haciendas. } \\
\text { Falta de adaptación al cambio climático. }\end{array}$ \\
\hline $\begin{array}{l}\text { Solución Sur } \\
\text { (Posibilidad B) } \\
\text { (Segura } \\
\text { Transparente) }\end{array}$ & $\begin{array}{l}\text { Encauzamiento de la rambla } \\
\text { de Abanilla, construyendo un } \\
\text { canal paralelo al río Segura para } \\
\text { evacuar las aguas de crecida de } \\
\text { la rambla de Abanilla hasta la } \\
\text { desembocadura. }\end{array}$ & $\begin{array}{l}\text { Creación de nuevas zonas inundables } \\
\text { Nulo funcionamiento en caso de desbordamiento del río Segura. } \\
\text { Modificación del sistema de riego (acequias y azarbes) } \\
\text { Coste de la obra muy elevado } \\
\text { Nulo aprovechamiento de las aguas pluviales } \\
\text { Falta de adaptación al cambio climático. }\end{array}$ \\
\hline
\end{tabular}

Fuente: Documento de propuestas Plan Vega Baja Renhace (2020). Elaboración propia. 
FIGURA 18.

PROPUESTAS PLANTEADAS EN EL PLAN VEGA BAJA RENHACE.

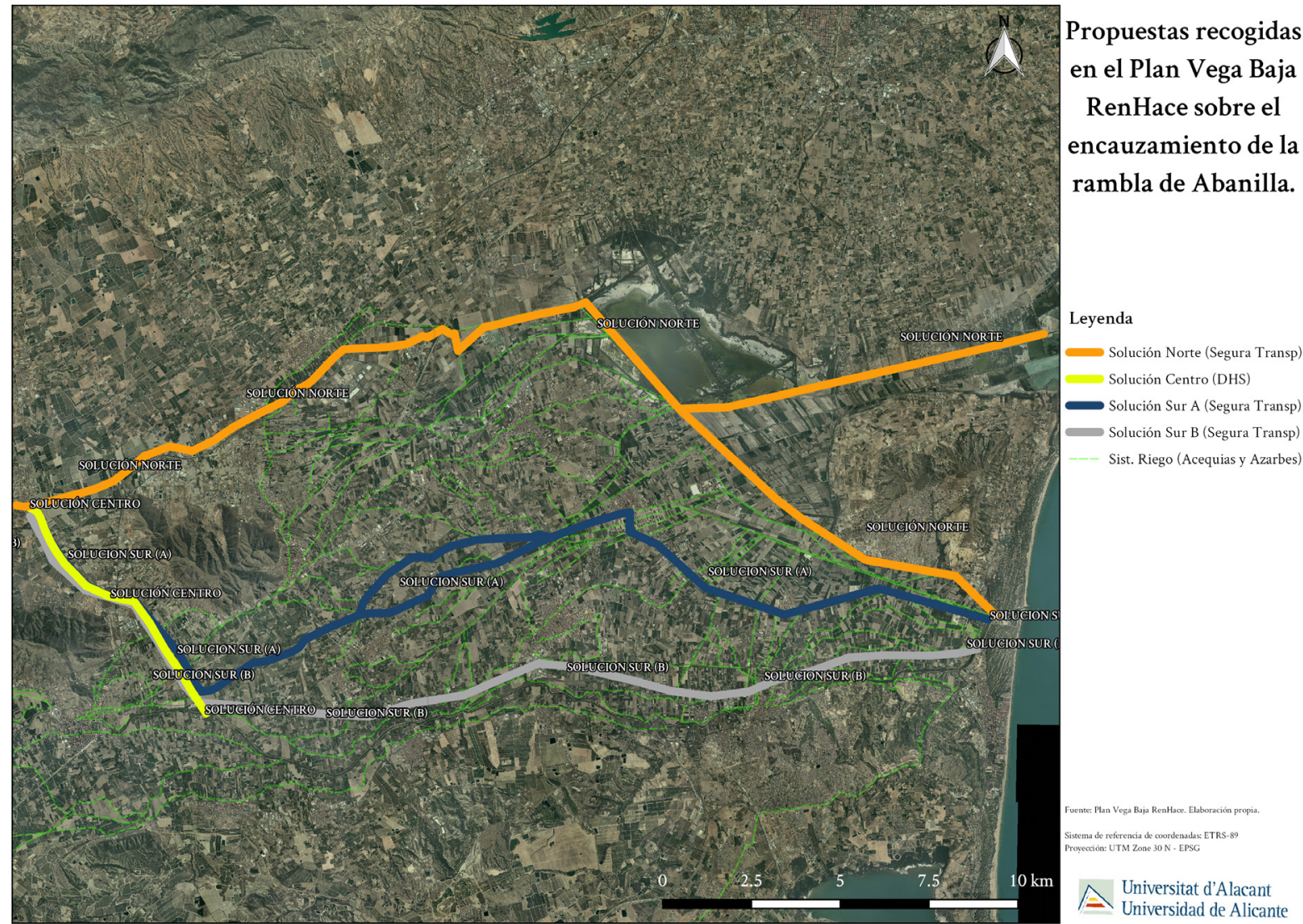

Elaboración propia.

- En primer lugar, el encauzamiento de la rambla de Abanilla por tramos generará una mayor velocidad de las aguas, por ende, una mayor virulencia de las mismas. Asimismo, las motas del encauzamiento estrecharían el cauce de manera que el calado incrementaría y podría favorecer el desbordamiento de la avenida. Ambas cuestiones suponen el incremento de la peligrosidad de la propia rambla, y en caso de fallo, la multiplicación de sus efectos perniciosos.

- En segundo lugar, la desviación de las aguas de avenida de la rambla de Abanilla hacia el río Segura tiene su complejidad. Dos recientes episodios de lluvias copiosas en diciembre de 2016 y en septiembre de 2019, han demostrado que el encauzamiento del río Segura queda al límite de la crecida máxima registrada, especialmente en el segundo de los episodios $\left(400 \mathrm{~m}^{3} / \mathrm{s}\right)$. En ambos episodios el río Segura se desborda en el centro de la ciudad de Orihuela, por lo que dichas aguas continúan desbordadas afuera de la ciudad. Si en este espacio se conecta la rambla de Abanilla con el río Segura, se estaría aportando mayores volúmenes de agua, que complicarían la capacidad de evacuación del encauzamiento realizado en el Plan de Defensa de Avenidas de la cuenca del Segura, tras la inundación de noviembre de 1987. Y a ello pueden unirse las propias aguas del Reguerón, - la avenida que pudiera proceder del Guadalentín y que se sumaría a los propios caudales de crecida del río Segura; de manera que las consecuencias aguas abajo a partir de estos puntos pueden ser desastrosas para los municipios situados en los propios márgenes del río, así como los que se encuentran ocupando la llanura de inundación del mismo. Asimismo, en el episodio de septiembre de 2019 se produjeron varias roturas de las motas del encauzamiento del Segura, lo que va a requerir una labor de revisión y mantenimiento de motas en el encauzamiento para que su capacidad 
no pueda fallar. Es por ello que esta propuesta debe estudiarse muy bien, con pros y contras ambientales y económicos, antes de su posible realización.

- En tercer lugar, la desviación de la rambla de Abanilla por el norteo por el sur, conectándolo con azarbes de la red de riegos existentes en la Vega debe calibrarse bien, debido a la propia singularidad de la red de riegos de la Vega Baja del Segura. Los azarbes de la llanura de inundación del Segura no presentan capacidad mayores a 10-15 $\mathrm{m}^{3} / \mathrm{s}$ aproximadamente, frente a la crecida de la rambla de Abanilla que puede oscilar entre los $100-300 \mathrm{~m}^{3} / \mathrm{s}$ o más por su cauce. Ello podría generar el desbordamiento de los mismos, el embarrado y la afección de zonas que antes no presentaban problemas de inundación. Dicho de otra manera, se estaría creando nuevos espacios inundables que podrían verse afectados ante la impetuosa avenida de la rambla de Abanilla. Asimismo, los azarbes ya se desbordan por la propia lluvia in situ y crecida del río Segura, por lo que no tendrían ninguna capacidad de avenamiento de la enorme avenida de la rambla de Abanilla. En caso de que se ampliasen los azarbes, todavía sería cuestionable ya que para construir un canal seguro, debería presentar unas dimensiones considerables por lo que incrementa el coste, además de una longitud que partiría desde la rambla de Abanilla hasta la desembocadura del Segura. Del mismo modo, conviene señalar que siempre ha habido problemas de inundación y estancamiento de aguas en el tramo final de los azarbes en su desembocadura con el cauce antiguo del Segura, como para potenciarlo aún más. Este problema podría verse agravado, si encima se le suman los caudales de la rambla de Abanilla.

- En cuarto lugar, además de las posibles zonas que podrían contaminarse, del desaprovechamiento de las aguas pluviales, o que son obras que no se adaptan a los escenarios futuros sobre el cambio climático; todas estas obras implican, en mayor o menor grado, la destrucción de un patrimonio cultural-histórico como es la propia huerta. Asimismo, la destrucción de gran parte del patrimonio hidráulico-histórico desde época romana-islámica datada de más de 700 años.

He aquí donde entra en juego la importancia de la cartografía histórica. Como se ha visto en la Figura 4, antiguamente, a lo largo del río Chícamo y la rambla de Abanilla sensu stricto, existía todo una red de sistema de boqueras encargadas de derivar las aguas de avenida del cauce, por medio de acequias o boqueras de diferentes niveles, hacia los campos de cultivos más próximos, de forma que se captaba el agua para riego e incluso abastecimiento, si disponían de la presencia de piscinas, balsas o aljibes. Esta cultura del agua, ha ido desapareciendo con las transformaciones territoriales por parte del hombre en el territorio. No obstante, todavía quedan vestigios de estas infraestructuras, de las cuales algunas de ellas se siguen utilizando hoy en día. El problema radica en la irregularidad de las lluvias provocan que el cauce se encuentre seco la mayor parte del año, lo que se traduce en una nula o escasa rentabilidad y en el aprovechamiento de este recurso. Sin embargo, conviene recordar que este sistema de derivación de agua cumplía con dos funciones esenciales: aprovechamiento del agua pluvial para riego y la reducción de la peligrosidad y, por ende, del riesgo de inundación, al reducirse los caudales circulantes.

En este sentido, deben encaminarse las propuestas conociendo la capacidad técnica y tecnológica de estos tiempos, a la vez que resultan más viables y menos costosas, desde un punto de vista ecológico, social y económico.

Las propuestas elaboradas en este trabajo y recogidas en la Tabla 4, son menos costosas ambiental y económicamente, y permitirían poner en práctica otro tipo de actuaciones más eficaces respecto al riesgo de inundación. Si bien, debe señalarse que se trata de medidas ideadas para crecidas ordinarias, puesto que una crecida extraordinaria como la ocurrida en el episodio de septiembre de 2019 requeriría de un tratamiento integral de la cuenca que contemple, junto a las propuestas por este estudio, la realización de presas de laminación en el tramo alto y medio, y un encauzamiento, lo menos impactante ambientalmente posible, en el tramo bajo.

Ello no implica que no se vayan a producir desbordamientos ni anegaciones, pero sí que permite afirmar que los efectos perniciosos de las mismas serán menores. Conviene recordar que la Directiva $60 / 2007 / C E$, en su consideración número 2 , señala que "las inundaciones son fenómenos naturales que no se pueden evitar" por lo que la apuesta principal debe ser la gestión del riesgo.

Esta cuestión se relaciona directamente con el cambio climático. En efecto, como señalan los escenarios 
TABLA5.

PROPUESTAS PARA SOLVENTAR LOS PROBLEMAS DE INUNDACIÓN DE LA RAMBLA DE ABANILLA.

\begin{tabular}{|c|c|}
\hline PROPUESTAS & DESCRIPCIÓN \\
\hline $\begin{array}{l}\text { Restauración y reforestación } \\
\text { de la cuenca alta de la } \\
\text { rambla de Abanilla }\end{array}$ & $\begin{array}{l}\text {-El objetivo de esta propuesta viene siendo aprovechar la reforestación con especia autóctonas de las cuencas altas y media } \\
\text { con la finalidad de estabilizar el suelo y protegerlo de la erosión. Asimismo, se reduce la carga sólida arrastrada por las } \\
\text { aguas, disminuyendo su virulencia y su calado. }\end{array}$ \\
\hline $\begin{array}{l}\text { Recuperación los sistemas } \\
\text { de aprovechamiento } \\
\text { tradicionales }\end{array}$ & $\begin{array}{l}\text {-Se hace referencia a la recuperación de los métodos tradicionales de captación y aprovechamiento de las aguas pluviales: } \\
\text { aterrazamientos, sistemas de derivación (boqueras/acequias) y aljibes. }\end{array}$ \\
\hline $\begin{array}{l}\text { Modernización de los } \\
\text { sistema tradicionales de } \\
\text { aprovechamiento }\end{array}$ & $\begin{array}{l}\text {-Aprovechando la capacidad tecnológica y técnica de hoy en día, los sistema de derivación de agua podrían controlarse } \\
\text { por medio de controles remotos, gestionados por los SAIH, de manera que en un episodio de inundación pueda desviar las } \\
\text { aguas por la red de boqueras, evitando la llegada de agua en municipios que se encuentren anegados o incluso para una } \\
\text { mayor gestión y eficiencia de los riegos. }\end{array}$ \\
\hline $\begin{array}{l}\text { Creación de zonas } \\
\text { inundables }\end{array}$ & $\begin{array}{l}\text {-Conociendo el comportamiento del agua, en aquellos espacios que ocupan grandes superficies o se encuentran próximos } \\
\text { al cauce, podrían transformarse en espacios inundables, de manera que permita almacenar cierta cantidad de agua de } \\
\text { las avenidas. Por ejemplo: En la margen derecha de la rambla Abanilla, antes de llegar al núcleo de Benferri, se localiza el } \\
\text { campo municipal de fútbol de "Luís de Rocamora", el cual se podría construir un depósito que pudiera almacenar parte de } \\
\text { las aguas pluviales y de las avenidas. Colindante a éste, se encuentra un espacio que parece ser una cantera o un espacio de } \\
\text { obtención de materiales que presenta una profundidad interesante para convertir dicho espacio en una zona inundable, de } \\
\text { manera que capte gran parte del volumen de escorrentía circulante por la rambla de Abanilla. Asimismo, se podría convertir } \\
\text { en un depósito o aljibe gigante, que capte las aguas y que permite almacenarlas para, posteriormente, redistribuirlas por } \\
\text { los campos de cultivo. } \\
\text {-Otra zona que podría convertirse en un espacio inundable corresponde al antiguo Pantano de las Fuentes, actual Palmeral } \\
\text { de San Antón, aprovechando las medidas del mismo para captar las aguas finales de las avenidas de la rambla de Abanilla, } \\
\text { las pluviales, y las que descienden en torrenteras de la sierra de Orihuela y monte de San Miguel. De esta manera, también } \\
\text { se estaría reduciendo, en parte, la vulnerabilidad de este espacio, ya que se encuentran ubicados institutos y colegios en } \\
\text { esta zona inundable. } \\
\text {-Para Redován, la opción más viable sería generar una red de boqueras para desviar las aguas hacia los campos de cultivos y } \\
\text { crear espacios inundables de manera exclusiva. } \\
\text { Asimismo, existen dos canteras, en el sector W y NW de la sierra de Callosa del Segura que podrían utilizarse de balsa como } \\
\text { área de sacrificio para captar las aguas de las crecidas ordinarias, así como de las pluviales que descienden del relieve. La } \\
\text { creación de un espacio verde, que permita almacenar y reducir la lámina de agua antes de llegar a la zona baja, permitiría } \\
\text { reducir la peligrosidad. En estos espacios, se deberán plantar árboles y arbustos que frenen las rocas que se desprendan de } \\
\text { la sierra en lluvias intensas. }\end{array}$ \\
\hline $\begin{array}{l}\text { Creación de zonas de } \\
\text { depósitos de materiales. }\end{array}$ & $\begin{array}{l}\text {-Junto con la creación de zonas inundables, se plantea la creación de espacios que recojan los materiales o carga sólida } \\
\text { arrastrada por la avenida, de manera que el suelo que se pierda por erosión, pueda aprovecharse para otros espacios y } \\
\text { cultivos pobres en suelo. Conviene recordar que la mezcla del agua y los materiales arrastrados forman suelos muy aptos y } \\
\text { fertilizantes para los cultivos. }\end{array}$ \\
\hline Ordenación del territorio & $\begin{array}{l}\text {-Las viviendas situadas en el lecho de inundación de la rambla de Abanilla, en el barrio del Cabezo (Benferri), deben ser } \\
\text { demolidas, priorizando la salvaguarda de las vidas humanas de este espacio. Para ello, se plantea que se les indemnice con } \\
\text { otra vivienda situada en el núcleo de Benferri. Asimismo, se favorece a la recuperación y restauración hidrológica del cauce. } \\
\text {-A ser posible, trasladar los colegios e institutos ubicados en la zona del Palmeral de San Antón, al situarse en una antigua } \\
\text { zona lacustre y siendo un espacio de alto riesgo. } \\
\text {-Elaboración de cartografía de riesgo (Peligrosidad * Vulnerabilidad) a escala municipal o detalle. } \\
\text {-Elaboración de un Plan de Emergencias municipal (Benferri, Redován y Cox) para saber gestionar cualquier riesgo. } \\
\text {-Evitar nuevas construcciones en zonas inundables. } \\
\text {-Elevar las carreteras para facilitar la circulación de las aguas. }\end{array}$ \\
\hline
\end{tabular}

de cambio climático y numerosas investigaciones, la frecuencia de los fenómenos meteorológicos extremos se va a incrementar, lo que se traduce en una mayor frecuencia e intensidad en las inundaciones y las sequías. Asimismo, coinciden que se va a producir una reducción en la cantidad de recursos hídricos disponibles por el descenso de hasta un $10 \%$ de las aguas superficiales (CEDEX, 2012; IPCC, 2013-2014,
2018 y 2019; Sillero Medina, Hueso González y Ruiz Sinoga; Olcina, 2019; Olcina y Oliva, 2020; AEMET, 2020;Dottori, Mentaschi, Bianchi Alfieriy Feyen, 2020). En el caso de la cuenca del Mediterráneo, la situación atmosférica que provoca las lluvias torrenciales y las inundaciones, son los embolsamientos de aire frío en las capas altas de la troposfera, conocidas como gotas frías o Depresiones Aisladas en los Nive- 
les Altos (DANA), con circulación de vientos de levante, generalmente, en superficie. Los últimos estudios señalan que desde el año 2000 se están produciendo un mayor número de situaciones de gota fría respecto a décadas anteriores del siglo pasado, relacionado directamente con el proceso de calentamiento climático actual y muy especialmente con los efectos que se manifiestan de forma evidente en la cuenca ártica (Muñoz et al., 2020).Asimismo, se señala que las precipitaciones intensas y torrenciales, ya no se centran exclusivamente en los meses de otoño, sino que pueden darse en cualquier época del año (Olcina y Oliva, 2020b). Por lo tanto, el territorio debe adaptarse a estas circunstancias, es decir, debe prepararse para poder asumir los efectos de las precipitaciones que descargan grandes cantidades en periodos breves de tiempo (30 min. - 1 hora) (Olcina, 2019), obteniendo de ellas un recurso para afrontar las sequías.

La cuestión de la adaptación al cambio climático y su relación con las inundaciones resulta fundamental comprenderla, ya que los escenarios futuros señalan que el continuo desarrollo de las actividades humanas, ocupando zonas inundables, siguen incrementando lo que se deriva en un mayor riesgo de inundación. Asimismo, se señala que los daños directos de las inundaciones podrían ser seis veces mayores que las pérdidas actuales a finales del siglo sino se produce una mitigación y adaptación al clima (Dottori et al., 2020)

Como se ha recogido en la tabla de propuestas, en el contexto europeo se ha realizado un estudio en el que se apuesta por la creación de espacios inundables o áreas de retención para reducir los picos de crecidas y disminuir los impactos de manera rentable en la mayoría de los países de la Unión Europea. Sobre todo, porque reduce entre un 63-81\% los efectos de la población expuesta, así como el daño económico, cuyos porcentajes oscilante entre el 64-82\% (Dottori et al., 2020). Por tanto, esta medida junto a las propuestas en la Tabla 4 son las líneas a seguir para solucionar los problemas de inundación en la Vega Baja del Segura.

A estos efectos, las inundaciones se plantean como una oportunidad. Si históricamente éstas cumplían con una doble finalidad: reducción del riesgo de inundación y aprovechamiento de las aguas pluviales; hoy en día, presentarían cinco funciones:

a) Reducción del riesgo de inundación

b) Aprovechamiento del agua pluvial (Captación, derivación y almacenamiento) c) Medida de adaptación al cambio climático.

d) Recurso o fuente alternativa para combatir las sequías.

e) Recuperación y puesta en valor del Patrimonio histórico hidráulico.

El aprovechamiento de un peligro natural como son las inundaciones para combatir con las sequías debe ser la línea a seguir en las futuras investigaciones, puesto que se puede considerar como una medida paliativa a sus efectos negativos dentro del contexto del calentamiento global. Asimismo, los efectos derivados de las sequías, como pueden ser los incendios forestales, también pueden resolverse por medio del aprovechamiento del agua de lluvia, manteniendo los terrenos de forma húmeda de manera que se reduzcan las condiciones de propagación de incendio, además de servir para la extinción de incendios.

Se trata, en definitiva, de hacer de la necesidad, virtud; y aprovechar un recurso escaso como es el agua, convertido en amenaza por medio de las inundaciones, en una oportunidad de adaptación y aprovechamiento para mitigar los efectos del cambio climático.

\section{CONCLUSIONES}

La presente investigación ha mostrado que la cartografía histórica resulta un recurso muy útil para conocer las zonas por donde ha circulado el agua de manera natural o por intervención humana en el pasado y que, en ocasiones, recupera su espacio fluvial. Ello ha permitido, junto con la superposición de otros mapas temáticos y la modelización correspondiente, la obtención de un mapa de peligrosidad que ha tenido en cuenta, también, los efectos padecidos en esta área por el episodio de lluvias torrenciales de septiembre de 2019. Asimismo, se plantea la necesidad de completar este estudio con aspectos relacionados con la vulnerabilidad que terminen configurando un mapa de riesgo de inundación a escala local y regional.

Asimismo, se ha demostrado que existe una elevada peligrosidad de inundación en el tramo bajo de la rambla de Abanilla, en la cual los municipios más afectados son: Benferri, Redován, Cox y Orihuela. Estos municipios presentan espacios ocupados por acción la antrópica en zonas inundables, y en los que se pone en riesgo la vida humana, como quedó manifiesto en el señalado episodio de inundación acaecido en septiembre de 2019, en el que se produjo una víctima mortal del municipio de Redován. 
Se ha analizado las medidas y soluciones planteadas por parte de los organismos públicos y se ha explicado la dificulta de su puesta en práctica y la necesidad de analizar con detalles los pros y contras ambientales y económicos de su posible desarrollo. Por ello se han planteado una serie de propuestas que permitirían adaptarse al cambio climático, reducir el riesgo de inundación y aprovechar las aguas pluviales para riego y abastecimiento; en definitiva, para transformar el peligro natural en un recurso, favoreciendo un mayor respeto por el medio natural. En este sentido, deben dirigirse las investigaciones futuras sobre el riesgo de inundaciones en áreas de elevada peligrosidad, en la búsqueda de alternativas que permitan convertir la amenaza de las inundaciones en una oportunidad, y que, a su vez, sirvan como medidas de adaptación al cambio climático, cuyos efectos se evidencian ya en el territorio español, y muy especialmente, en las regiones del litoral mediterráneo.

\section{REFERENCIAS BIBLIOGRÁFICAS}

Agencia Estatal de Meteorología (AEMET) (2020). Proyecciones climáticas para el siglo XXI. Disponible en: http://www.aemet.es/es/serviciosclimaticos/ cambio_climat [Última consulta 08/04/2021] [En línea].

Balboa Zaragoza, E. (1997). Ocupación antrópica de ramblas y barrancos en la comarca del Bajo Segura (Alicante): Análisis-Diagnóstico de la situación en alguno de sus municipios. Investigaciones Geográficas, (17), 149-162.

Bernabé Gil, D. (1999). Insalubridad y bonificaciones de almarjales en el Bajo Segura antes de la Pías Fundaciones de Belluga. Revista de Historia Moderna, (17), 45-72.

Box Amorós, M. (1995). Un aprovisionamiento tradicional de agua en el sureste ibérico: los aljibes. Investigaciones Geográficas, 1995, (13), 91-106. doi: http://dx.doi.org/10.14198/INGEO1995.13.01

Castillo Meseguer, M., Calero Sáez, M., Palao García, M., Pérez Bolumar, M.S., Rodríguez Pérez, M. T. y Gómez Espín, J. M. (1995). Molinos hidráulicos en la cuenca de Fortuna-Abanilla (Murcia). Los aprovechamientos de la red del río Chícamo y el manantial de Los Baños. Papeles de Geografía, 2 (22), 33-51. Recuperado a partir de https://revistas.um.es/geografia/article/view/44711

Cavanilles, J.A. (1795-1797). Observaciones sobre la Historia Natural, Geografía, Agricultura, Po- blación y Frutos del Reyno de Valencia. Madrid: Imprenta Real: siendo gerente D. Pedro Julián Pereyra, Tomo II, 369 p. Extraído de la Biblioteca Valenciana. Recuperado de https://bivaldi.gva.es/ es/consulta/registro.do?id=285

CEDEX (2012). Estudio de los impactos del cambio climático en los recursos hídricos y las masas de agua (Centro de Estudios Hidrográficos, Ed.). doi:https://doi.org/10.1017/ CBO9781107415324.004

Coello, F. (1859). Diccionario geográfico-estadísticohistórico. Atlas de España y sus posesiones de Ultramar. Alicante (Provincia). Mapas generales. 1859. Madrid: [s.n]. Biblioteca Nacional de España-Biblioteca Digital Hispánica. Recuperado de http://bdh.bne.es/bnesearch/detalle/ bdh0000022257

Dottori, F., Mentaschi, L., Bianchi, A., Alfieri, L. and Feyen, L. (2020). Adapting to rising river flood risk in the EU under climate change.Joint Research Centre (JRC). Peseta IV Project-Task 5. Luxembourg: Publications Office of the European Union. Retrieved from: https://publications.jrc.ec.europa.eu/ repository/handle/JRC118425

España. Ministerio de Agricultura, Alimentación y Medio Ambiente. Confederación Hidrográfica del Segura (2015). Plan Hidrológico de la Demarcación del Segura 2015-2021 [Memoria]. 806 p. Recuperado de: https://www.chsegura.es/chs/planificacionydma/planificacion15-21/

España. Ministerio para la Transición Ecológica y el Reto Demográfico. Confederación Hidrográfica del Segura (2020). Esquema Provisional de Temas Importantes de la Demarcación 2021-2027 [Completo] Tercer ciclo de planificación hidrológica. 419 p. Recuperado de: https://www.chsegura.es/chs/planificacionydma/planificacion21-27/proceso.html

ESPON (2006). The Spatial Effects and Management of Natural and Technological Hazards in Europe (P. Schmidt-Thomé, Ed.). doi: https://doi. org/10.1016/S0264-410X(12)01439-9.

Generalitat Valenciana. Conselleria d'Habitatge, Obres Pùbliques y Vertebració del Territori (2015). Plan de Acción Territorial de carácter sectorial sobre la prevención del Riesgo de Inundación en la Comunitat Valenciana (PATRICOVA) [Memoria]. Recuperado de: http://politicaterritorial.gva.es/docu ments/20551069/162377494/01+Memoria/9938 fc0e-3ba8-4829-8524-5d3afa3542eb 
Generalitat Valenciana (2020). Plan Vega Baja Renhace. Proyectos. Aportaciones en el proceso de participación ciudadana. 19 p. Recuperado de: http:// www.presidencia.gva.es/es/web/vega-Renhace

Gil Meseguer, E. y Gómez Espín, J.M. (2012). Del riego tradicional en los oasis del Chícamo a los regadíos modernizados del postrasvase Tajo-Segura en Abanilla (Región de Murcia-España). Nimbus, (2930), 289-303. ISSN: 1139-7136.

Giménez Font, P. (2009). Cartografía histórica y alteración de cursos fluviales en la España mediterránea. En: Alberola, A. y Olcina Cantos (Eds), Desastre natural, vida cotidiana y religiosidad popular en la España moderna y contemporánea, pp. 391432. ISBN: 978-84-7908-552-0. San Vicente del Raspeig, España: Publicaciones de la Universidad de Alicante.

Instituto Cartográfico Valenciano (ICV). Fototeca digital. Vuelos de menor superficie y autonómicos. Vuelo Ruiz de Alda. Cuenca Hidrográfica del Segura (1929-1930) y vuelo Americano Serie B (19561957).

Instituto Geográfico Nacional (IGN). Centro de Descargas del CNIG. Modelos Digitales de Elevación 05 m.

Inter-Agency Sanding Committee and European Commision (2020). Inform. Report 2020. Shared evidence for managing crises and disasters. Joint Research Centre (JRC). Luxembourg: Publication Office of the European Union. 48 p. Retrieved from: https://ec.europa.eu/jrc/en/publication/ inform-report-2020-shared-evidence-managingcrisis-and-disaster

Intergovernmental Panel on Climate Change (20132014). Cambio climático 2014: Informe de síntesis. Contribución de los Grupos de trabajo I, II y III al Quinto Informe de Evaluación del Grupo Intergubernamental de Expertos sobre el Cambio Climático (E. principal de Redacción, R. K. Pachauriy L. A. Meyer, Eds.). Ginebra, Suiza.

IPCC (2018). Global Warming of $1.5^{\circ} \mathrm{C}$. An IPCC Special Reporto on the impacts of global warming of $1.5^{\circ} \mathrm{C}$ above pre-industrial levels and related global greenhouse gas emission pathways, in the context of strengthening the global response to the threat of climate chage, (and T. W. Masson-Delmonte, V., P. Zhai, H.-O. Pörtner, D. Roberts, J. Skea, P.R. Shukla, A. Pirani, W. Moufouma-Okia, C. Péan, R. Pidcock, S. Connors, J.B.R. Matthew, Y. Chen, X. Zhou, M.I. Gomis, E. Lonnoy, T. Maycocck, M. Tignor, Ed.).
IPCC (2019). Climate Change and Land: an IPCC Special report on climate change, desertification, land degradation, sustainable land management, food security and greenhouse gas fluxes in terrestrial ecosystems.

Laboratorio de Climatología de la Universidad de Alicante (2019). Precipitación total registrada en el episodio de septiembre de 2019. Recuperado de: https://www.facebook.com/labclimaUA/photos /a.487357624770773/1660184870821370

Madoz, P. (1845-1850). Diccionario geográfico-estadístico-histórico de España y sus posesiones de Ultramar. Madrid: [s.n] (Imp. P. Madoz y L. Sagasti, etc.) Biblioteca Digital Hispánica. 2a edición. Tomos I-XVI, 5.944 p. Recuperado de http://bdh.bne.es/bnesearch/ CompleteSearch.do?languageView=es\&field=todos \&text=pascual+madoz\&showYearltems $=\&$ exact $=$ on \&text $\mathrm{H}=$ \&advanced=false \&completeText=\&pageSiz $\mathrm{e}=1$ \&pageSizeAbrv=30\&pageNumber $=5$

Manzano Garro, T. (1987). Características morfométricas del río Chícamo. Cuenca Abanilla-Fortuna (Sureste de España). Paralelo 37, (11-12), 107-112. ISSN: 0210-3796.

Marco Molina, J. A., Giménez Font, P., Padilla Blanco, A., García Botella, E., \& Prieto Cerdán, A. (2020). La rambla de Abanilla-Benferri como paradigma para el estudio del conocimiento tradicional relativo al aprovechamiento de las aguas de avenida. En: López Ortiz, M. I., \& Melgarejo Moreno, J. (Eds.). Riesgo de Inundación en España: análisis y soluciones para la generación de territorios resilientes. Congreso Nacional de Inundaciones (Orihuela), pp. 881-896.

Morales Gil, A. (1969). El riego con aguas de avenida en las laderas subáridas. Papeles de Geografía, (1), 167183. Recuperado a partir de https://revistas.um.es/ geografia/article/view/41261

Morote Seguido, A. (2013). El aprovechamiento de turbias en San Vicente del Raspeig (Alicante) como ejemplo de sistema de riego tradicional y sostenible. Investigaciones Geográficas, (59), 147-169. doi: http://dx.doi.org/10.14198/INGEO2013.59.09

Muñoz, C., Schultz, D. y Vaughan, G. (2020). A Midlatitude Climatology and Interannual Variability of 200and 500-hPa Cut-Off Lows. Journal of Climate, 33 (6), 2201-2222.

Olcina Cantos, J. (1994). Tormentas y granizadas en las tierras alicantinas. Alicante: Universidad de Alicante, Instituto Universitario de Geografía, 1994. ISBN: 84-7908-146-5, 317 p. 
Olcina Cantos, J. (2009). Cambio climático y riesgos climáticos en España. Investigaciones Geográficas, (49), 197-220. ISSN: 0213-4691. Recuperado de https://doi.org/10.14198/INGEO2009.49.10

Olcina Cantos, J. (2019). Evidencias e incertidumbres del cambio climático y de los riesgos asociados en el litoral mediterráneo español. Real Sociedad Geográfica, CLIV, 9-34.

Olcina Cantos, J. y Oliva Cañizares, A. (2020a). Medidas estructurales versus cartografía de inundación en la valoración del riesgo en áreas urbanas: El caso del barranco de las Ovejas (Alicante, España). Cuadernos Geográficos, 59 (2), 199-220. Recuperado de https://doi.org/10.30827/cuadgeo.v59i2.10278

Olcina Cantos, J. y Oliva Cañizares, A. (2020b). "Gota fría" de septiembre de 2019 e inundaciones en la Vega Baja del Segura. Causas atmosféricas y efectos territoriales. Propuestas de actuación. En: Grupo Trabajo Vega Baja. Informe "La Cultura como elemento de progreso en la Vega Baja" (Anexo 5, pp. 87-128).Valencia, España: Consell Valencià de Cultura. Recuperado de: https://cvc. gva.es/wp-content/uploads/656-1.pdf

Parlamento y Consejo Europeo (2007). Directiva $60 / 2007 / C E$, de 23 de octubre de 2007, relativa a la Evaluación y Gestión de los Riesgos de Inundación. 27-34.

Pérez Morales, A., Gil-Guirado, S., y Olcina, J. (2015). Housing bubbles and the increase of flood exposure. Failures in flood risk management on the Spanish south-eastern coast (1975-2013). Jorunal of Flood Risk Management, 11(2018), S302-S313. Doi: https://doi.org/10.1111/jfr3.12207

Perles Roselló, M. J., Olcina Cantos, J. y Mérida Rodríguez, M. (2018). Balance de las políticas de gestión del riesgo de inundaciones en España: de las acciones estructurales a la ordenación territorial. Ciudad y Territorio, L (197), 417-438. ISSN: 11334762.

Sánchez Almodóvar, E. (2018). Recursos hídricos no convencionales en Aspe: Un modelo local de gestión integrada del riesgo de inundación y del aprovechamiento conjunto de aguas residuales y de la escorrentía urbana. (Trabajo Fin de Máster o Tesis de maestría). Recuperado de: http://rua.ua.es/ dspace/handle/10045/76907

Sillero Medina, J. A., Hueso González, P., y Ruiz Sinoga, J.D. (2019). La precipitación geomorfológica como elemento clave en el modelado del paisaje mediterráneo. Boletín de La Asociación de Española de Geografía, (82), 1-40.

Soriano Andreu, F. (2004). Análisis del riesgo de inundación en los municipios meridionales de Alicante: comarcas del Bajo Vinalopó y Bajo Segura. En: Gil Olcina, A., Olcina, J. y Rico Amorós, A.M. (Eds.), Aguaceros, aguaduchos e inundaciones en áreas urbanas alicantina. (pp. 527-624). San Vicente del Raspeig, España: Publicaciones de la Universidad de Alicante.

White, G. F. (1945). Human adjustment to floods. A Geographical to the flood problem a in United States. University of Chicago, United States. 238 p. 